Check for updates

Cite this: RSC Adv., 2018, 8, 27359

Received 28th April 2018 Accepted 19th July 2018

DOI: $10.1039 / c 8 \mathrm{ra03658f}$

rsc.li/rsc-advances

\section{Small molecule generators of biologically reactive sulfur species}

\author{
Prerona Bora, Preeti Chauhan, Kundansingh A. Pardeshi and Harinath Chakrapani (D) * \\ Sulfur metabolism is integral to cellular growth and survival. The presence of a wide range of oxidation \\ states of sulfur in biology coupled with its unique reactivity are some key features of the biology of this \\ element. In particular, nearly all oxidation states of sulfur not only occur but are also inter-convertible. In \\ order to study the chemical biology of reactive sulfur species, tools to reliably detect as well as generate \\ these species within cells are necessary. Herein, an overview of strategies to generate certain reactive \\ sulfur species is presented. The donors of reactive sulfur species have been organized based on their \\ oxidation states. These interesting small molecules have helped lay a strong foundation to study the \\ biology of reactive sulfur species and some may have therapeutic applications in the future as well.
}

\section{Introduction}

Sulfur is an essential element for life and plays critical roles in cellular functioning and growth. The naturally occurring amino acids cysteine and methionine are important components of numerous proteins. Since the emergence of life on earth, sulfur chemistry has been intricately involved in a multitude of metabolic pathways, the versatility of which can be attributed to the interconvertible oxidation states of sulfur (Fig. 1). ${ }^{1}$ Reactive sulfur species are sulfur-derived entities that when generated within cells can mediate biological processes and be cytoprotective in nature and are hence deployed by cells for defence. ${ }^{2,3}$ In contrast, reactive sulfur species can also damage cellular

Department of Chemistry, Indian Institute of Science Education and Research Pune, Pune 411 008, Maharashtra, India.E-mail: harinath@iiserpune.ac.in components, typically at elevated concentrations. The emergence of these species parallels the development of reactive oxygen species (ROS) that cause oxidative stress and reactive nitrogen species (RNS) that lead to nitrosative stress, ${ }^{4}$ from sulfate, which has an oxidation state of +6 , to thiol/hydrogen sulfide, whose oxidation state is -2 with several intermediary states. Thus, nearly all these oxidation states occur in normal cells and may have critical roles to play in the functioning of cells.

\section{Reactive sulfur species}

The lowest oxidation state of sulfur includes reactive species like thiols, hydrogen sulfide $\left(\mathrm{H}_{2} \mathrm{~S}\right)$ and carbonyl sulfide (COS). $\mathrm{H}_{2} \mathrm{~S}$ is obtained from $\mathrm{L}$-cysteine via the transsulfuration pathway involving cystathionine- $\beta$-synthase (CBS), cystathionine- $\gamma$-lyase (CSE) and 3-mercaptopyruvate sulfur transferase (3-MST).$^{5-8}$ It

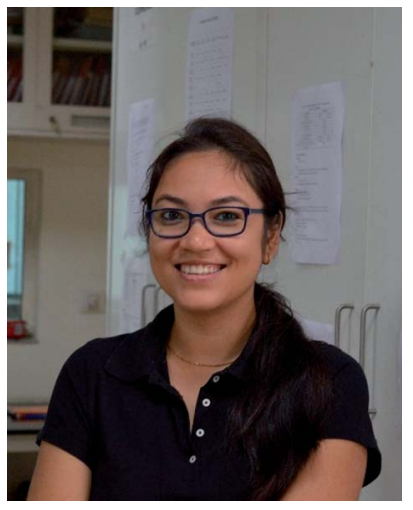

Prerona Bora completed her Bachelor's (2010-2013) in chemistry from Hindu College, University of Delhi and her Master's (2013-2015) in chemistry from Tezpur University. She has been enrolled in the PhD programme at Indian Institute of Science Education and Research (IISER) Pune from 2016. She is currently working under the supervision of $\mathrm{Dr}$ Harinath Chakrapani and her research interest involves synthesis and evaluation of small molecule sulfur based signaling molecules.

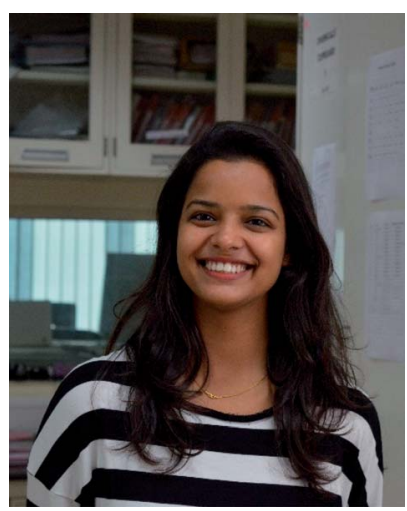

Preeti Chauhan has completed her BSc (2009-2012) and MSC (2012-2014) in chemistry from Hindu College, University of Delhi. She has been enrolled in the PhD programme at Indian Institute of Science Education and Research (IISER) Pune from August 2014. She is currently working towards her PhD under the supervision of Dr Harinath Chakrapani. Her research interest is to design and synthesize small molecule based tools for the delivery of hydrogen sulfide $\left(\mathrm{H}_{2} \mathrm{~S}\right)$ in a cellular system to explore the therapeutic potential of this gasotransmitter. 


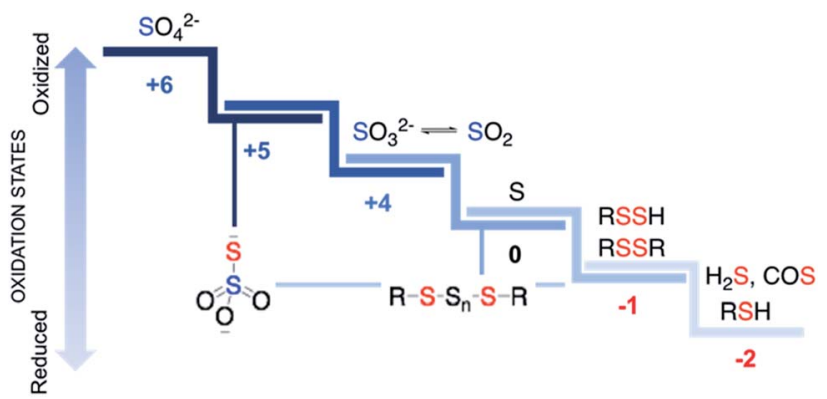

Fig. 1 Some biologically relevant reactive sulfur species. Red and blue are used to designate sulfur in negative and positive oxidation states respectively. Thiosulfate $\left(\mathrm{S}_{2} \mathrm{O}_{3}{ }^{2-}\right)$ and polysulfides have sulfurs in different oxidation states.

can interact metal centres in haemoglobin ${ }^{9}$ and cytochrome $c$ oxidase, ${ }^{\mathbf{1 0}}$ act as an antioxidant or carry out downstream signaling by S-sulfhydration of proteins. ${ }^{11} \mathrm{H}_{2} \mathrm{~S}$ can be oxidized by the mitochondrial flavo-protein sulfide quinone oxidoreductase (SQR) forming a transient persulfide intermediate that can potentially S-sulfhydrate proteins or act as a substrate for the sulfurtransferase rhodanese to form thiosulfate. ${ }^{12,13}$

Sulfite, which exists in equilibrium with $\mathrm{SO}_{2}$ can be generated by metabolism of L-cysteine by cysteine dioxygenase (CDO) and subsequently by aspartate aminotransferase (AAT).$^{\mathbf{1 4}}$ It can also be formed from thiosulfate in the presence of thiosulfate sulfurtransferase (TST). Interaction of sulfite with proteins via Ssulfonation is the most common pathway. However, the mechanisms by which $\mathrm{SO}_{2}$ elicits varied physiological roles are yet to be completely evaluated. ${ }^{\mathbf{1 5 , 1 6}}$ Sulfite oxidation is catalysed by sulfite oxidase (SO) to form sulfate that is eventually excreted in the urine. ${ }^{17}$ Sulfate can be obtained from the diet as well, taken up by the cell through sulfate transporters. Sulfate assimilation in all living organisms is activated by the enzyme ATP sulfurylase to form adenosine- $5^{\prime}$-phosphosulfate (APS) from ATP which subsequently gets converted to $3^{\prime}$-phosphoadenosine-5' $5^{\prime}$ phosphosulfate (PAPS), leading to sulfonation and detoxification of xenobiotics (Fig. 2). ${ }^{18-20}$ Dissimilation of sulfate by reduction is quite common in microbes and plants, however in mammals this pathway is yet unknown. This manuscript has been arranged accordingly to address each of the oxidation states that occurs in cells and describe chemical approaches to generating these species within cells.

An important reactive sulfur species is hydrogen sulfide $\left(\mathrm{H}_{2} \mathrm{~S}\right)$, which in the past two decades has become a major player in redox biology. Hydrogen sulfide $\left(\mathrm{H}_{2} \mathrm{~S}\right)$ is an important gaseous form of sulfur known for its lethal nature and toxicity for centuries. However, over past 15 years it has emerged as an important signaling molecule along with nitric oxide (NO) and carbon monoxide (CO). ${ }^{21-31}$ Chemical sources of $\mathrm{H}_{2} \mathrm{~S}$ is also proposed as an antioxidant and several small molecules are in various stages of pre-clinical evaluation for a number of indications. Being able to modulate levels of hydrogen sulfide may thus have tremendous potential in the treatment of certain pathophysiological conditions. A product of oxidation of hydrogen sulfide is sulfur dioxide $\left(\mathrm{SO}_{2}\right)$, which is notorious for its environmental polluting activity, acid rain and allergic reactions in certain individuals. ${ }^{32,33}$ Its hydrated form, sulfite, is also used in the food industry as a preservative and an antioxidant. ${ }^{34-36} \mathrm{SO}_{2}$ gas has also shown vasodilatory activity and may have regulatory roles as well. ${ }^{37}$

Thus, the fascinating chemical biology of the various redox forms of sulfur has triggered a lot of interest in systematically studying each of these forms in further detail. In order to do this, we need tools that can detect, generate as well as dissipate these species. Although most detection technologies have caveats associated with them, the use of multiple independent assays will help with enhanced reliability of detection of these species.

Specific dissipation (after generation) or inhibition of formation is another challenging problem. Most approaches have involved inhibiting a biosynthetic enzyme that catalyzes the formation of these species (in particular, hydrogen sulfide). ${ }^{38,39}$ Although a number of strategies are available, this

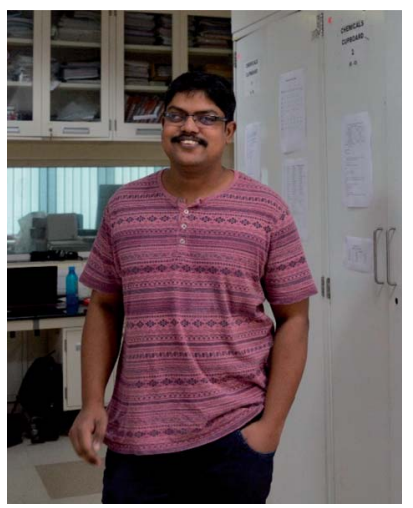

Kundansingh Pardeshi has completed his Bachelors (20052008) and masters (2008-2010) in chemistry from Dr B. Ambedkar Marathwada University, Aurangabad, Maharashtra. He enrolled in PhD programme at Indian Institute of Science Education and Research (IISER) Pune in Aug 2011. He is currently working under the supervision of $\mathrm{Dr}$ Harinath Chakrapani. His research interest involves design, synthesis and evaluation of bioactivable donors of sulfur dioxide $\left(\mathrm{SO}_{2}\right)$.

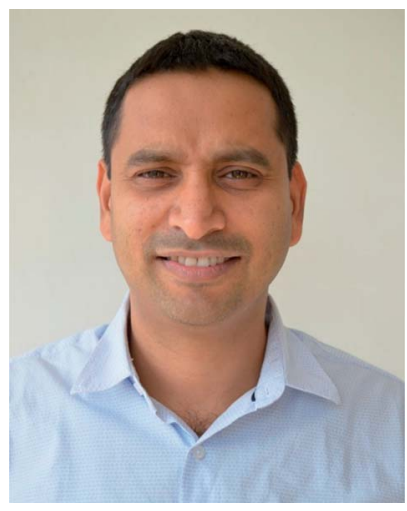

Harinath Chakrapani completed his undergraduate and postgraduate studies in Chemistry from Loyola College (1994-97) and Indian Institute of Technology Madras (1997-99), respectively. In the fall of 1999, he moved to Duke University, USA to pursue his doctoral studies, which he completed under the supervision of Prof. Eric J. Toone in Dec. 2005. His post-doctoral research work was carried out at Wake Forest University, where he worked with Prof. S. Bruce King and the National Cancer Institute, under the mentorship of Dr Larry K. Keefer. He joined IISER Pune in July 2009 and is currently Associate Professor. 


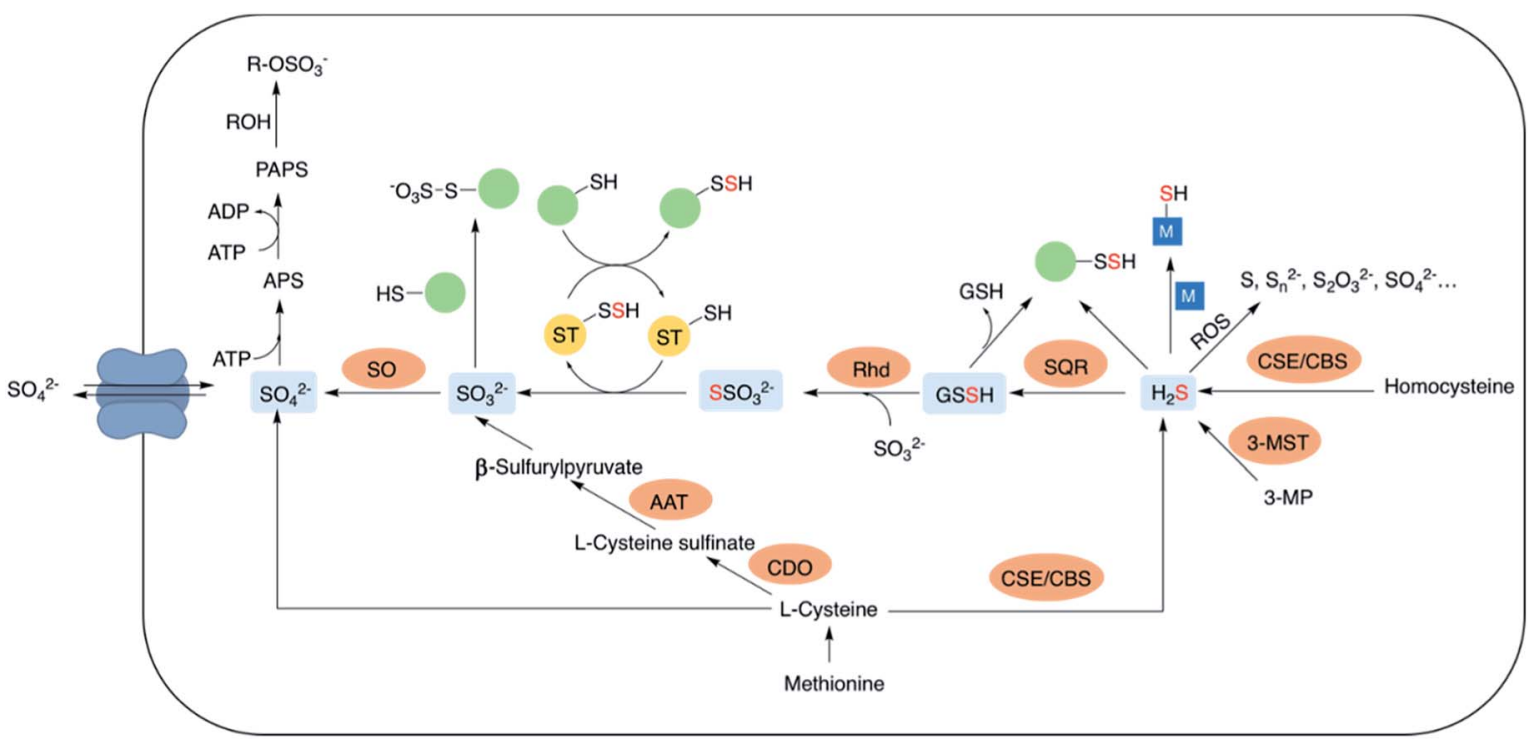

Fig. 2 A partial ensemble of sulfur oxidation states and their distinct physiological roles. CBS: cystathionine- $\beta$-synthase; CSE: cystathionine- $\gamma$ lyase; 3-MST: 3-mercaptopyruvate sulfurtransferase; SQR: sulfide quinone oxidoreductase; Rhd: rhodanese; SO: sulfite oxidase; AAT: aspartate aminotransferase; CDO: cysteine dioxygenase; APS: adenosine-5'-phosphosulfate; PAPS: $3^{\prime}$-phosphoadenosine-5'-phosphosulfate.

remains an unsolved problem and merits further attention. In this review, we cover the various strategies to generate reactive sulfur species within cells. The major challenges are to develop carriers or caged compounds that are triggerable within cells with minimal byproduct toxicity.

\section{Hydrogen sulfide}

The production of $\mathrm{H}_{2} \mathrm{~S}$ in cells is tightly regulated by the transsulfuration pathway enzymes. Therefore, abnormal changes in the level of $\mathrm{H}_{2} \mathrm{~S}$ could lead to various pathological conditions, for example - neurological disorders, cardiovascular diseases, gastrointestinal disorders, inflammation etc. Exogenous administration of $\mathrm{H}_{2} \mathrm{~S}$ under such conditions has proved beneficial which brings into picture the potential therapeutic effects of $\mathrm{H}_{2} \mathrm{~S}$. For example, exogenous administration of $\mathrm{H}_{2} \mathrm{~S}$ attenuates myocardial ischemia reperfusion injury. ${ }^{40}$ Also, being a reducing agent, it readily reacts with reactive oxygen and nitrogen species (RONS) to reduce inflammation and therefore acts as an anti-inflammatory agent. $\mathrm{H}_{2} \mathrm{~S}$ along with NSAIDs have been found to be more potent in treatment of gastrointestinal disorders as compared to NSAID alone. ${ }^{41,42}$ Therefore, to better explore the therapeutic potential of the gas and its mechanism of action, researchers from around the world have developed small molecule based $\mathrm{H}_{2} \mathrm{~S}$ donors. Many of the donors are covered in some excellent reviews and will therefore be briefly discussed here. ${ }^{40,43,44}$ Hydrogen sulfide donors have been classified in three major categories as naturally occurring, hydrolysis based $\mathrm{H}_{2} \mathrm{~S}$ donors, and triggerable $\mathrm{H}_{2} \mathrm{~S}$ donors. In particular, we shall cover some recent developments in the use of carbonyl sulfide (COS) as a source of $\mathrm{H}_{2} \mathrm{~S}$ and efforts to trigger the release of COS within cells.

Naturally occurring polysulfides have been derived from allium plants like garlic and onion which have been known for their beneficial health effects for centuries.$^{44}$ Consumption of garlic relates to the reduction in the risk of cardiovascular diseases such as high blood pressure, blood coagulation, and high cholesterol. ${ }^{45-47}$ These are rich source of organosulfur based polysulfides which are responsible for its pharmacological nature. Kraus and co-workers in 2007 showed that allicin which is produced upon crushing garlic rapidly decomposes to give diallyl based polysulfides - diallyl sulfide (DAS), diallyl disulfide (DADS) and diallyl trisulfide (DATS). Biological thiols like GSH and cysteine then act on these polysulfides to produce $\mathrm{H}_{2} \mathrm{~S}$ (Fig. 3). ${ }^{48}$

Other sources of naturally occurring $\mathrm{H}_{2} \mathrm{~S}$ donors include ovothiol from sea urchin eggs, leinamycin produced by streptomyces, ${ }^{49,50}$ and ergothioneine and lenthionine found in fungi. ${ }^{51}$ These natural products could act as potential antioxidant, antibacterial, antifungal and anti-cancer agents. The therapeutic potential of the naturally occurring $\mathrm{H}_{2} \mathrm{~S}$ donors is yet to be completely evaluated..$^{52,53}$

$\mathrm{NaSH}$ and $\mathrm{Na}_{2} \mathrm{~S}$ are inorganic salts which upon dissolving in water release $\mathrm{H}_{2} \mathrm{~S}^{54}$ The salts are widely used as source of $\mathrm{H}_{2} \mathrm{~S}$ but due to uncontrollable and burst release of sulfide, it is

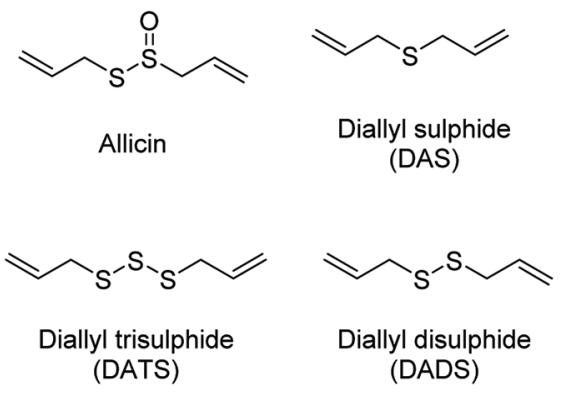

Fig. 3 Naturally occurring $\mathrm{H}_{2} \mathrm{~S}$ donors. 
difficult to maintain a constant concentration in a cell and therefore are not considered ideal for studying the physiological and pharmacological effects of $\mathrm{H}_{2} \mathrm{~S}$. Lawesson's reagent is a chemical compound used for sulfurization reactions in organic synthesis. ${ }^{55,56}$ It is used as a source of sulfide by researchers due to slower rate of $\mathrm{H}_{2} \mathrm{~S}$ release as compared to the inorganic salts. ${ }^{42,57}$ Thiophosphoryl chloride $\left(\mathrm{PSCl}_{3}\right)$ is another inorganic salt that is known to produce $\mathrm{H}_{2} \mathrm{~S}$ upon hydrolysis. ${ }^{58}$ However, the insoluble nature of these reagents limits its application.

Morpholin-4-ium 4 methoxyphenyl(morpholino) phosphinodithioate, GYY4137 a derivative of Lawesson's reagent, has better water solubility and produces $\mathrm{H}_{2} \mathrm{~S}$ at a slower rate. GYY4137 has been widely and extensively used for studying (patho)physiological roles of $\mathrm{H}_{2} \mathrm{~S}$. Low level of $\mathrm{H}_{2} \mathrm{~S}$ is maintained by GYY4137 even after 7 days. ${ }^{59,60}$ Although the donors exhibit $\mathrm{H}_{2} \mathrm{~S}$ like activities but due to unavailability of appropriate negative controls the observed activities cannot be attributed to $\mathrm{H}_{2} \mathrm{~S}$ production alone. Also, the rate of $\mathrm{H}_{2} \mathrm{~S}$ release cannot be controlled due to lack of an appropriate handle. And site directed delivery is not possible with these donors. 1,2Dithiole-3-thiones (DTTs) are yet another example of hydrolysis based $\mathrm{H}_{2} \mathrm{~S}$ donors which are synthesized by sulfurization and dehydrogenation reaction of allylic methyl group. DTT coupled with NSAIDs have showed significant reduction in the gastrointestinal damage caused by the parent NSAID. ${ }^{61-64}$ 5-(4Hydroxyphenyl)-3H-1,2-dithiole-3-thione (ADT-OH) is a derivative of DTT and has also been used as a potent $\mathrm{H}_{2} \mathrm{~S}$ donor. ADTNSAID hybrids have also shown therapeutic potential (Fig. 4a) ${ }^{41,65,66}$ The mechanism of action of the donors remains to be completely elucidated.

The concept of controllable $\mathrm{H}_{2} \mathrm{~S}$ donors was first introduced by Ming Xian and co-workers in the year 2011. They reported a series of $N$-(benzoylthio)benzamide derivatives which upon activation by cysteine form perthiols and further hydrolyse to produce $\mathrm{H}_{2} \mathrm{~S} .{ }^{67}$ Following a similar strategy, the same group reported cysteine perthiols protected with an acyl group. Cysteine perthiols are sensitive to glutathione (GSH) or cysteine and therefore get deprotected in the presence of thiols to yield $\mathrm{H}_{2} \mathrm{~S}{ }^{68}$ Having studied $\mathrm{N}$-SH and $\mathrm{S}$-SH based donors, dithioperoxyanhydrides were introduced in 2013 by Galardon and co-workers as thiol activated $\mathrm{H}_{2} \mathrm{~S}$ donors. ${ }^{69}$ Acylpersulfide was proposed as the key intermediate. Arylthioamides were also reported and categorized as thiol activated $\mathrm{H}_{2} \mathrm{~S}$ donors. ${ }^{70}$ However, the yield of $\mathrm{H}_{2} \mathrm{~S}$ produced from these donors was very low. Thiol activated gem dithiols were also reported as $\mathrm{H}_{2} \mathrm{~S}$ donors (Fig. $4 \mathrm{~b}$ ). ${ }^{71}$ Due to large abundance of thiols in nearly all cells, the above-mentioned donors have limited potential for site-directed delivery of $\mathrm{H}_{2} \mathrm{~S}$.

In an effort to further improve upon the existing donors and overcome the limitations, Ming Xian and co-workers reported pH controlled $\mathrm{H}_{2} \mathrm{~S}$ release based on GYY4137 scaffold (Fig. 4c). ${ }^{72}$ Donors were found to release $\mathrm{H}_{2} \mathrm{~S}$ only at $\mathrm{pH} 5.0$ and were stable at neutral and slightly alkaline $\mathrm{pH}$. In vivo studies demonstrated cardioprotective nature of these donors at low doses of 50 and $100 \mu \mathrm{gg}^{-1}$.

With an aim to achieve localized delivery of $\mathrm{H}_{2} \mathrm{~S}$ Ming Xian and co-workers reported light activated $\mathrm{H}_{2} \mathrm{~S}$ donors. Upon a) Hydrolysis based $\mathrm{H}_{2} \mathrm{~S}$ donors

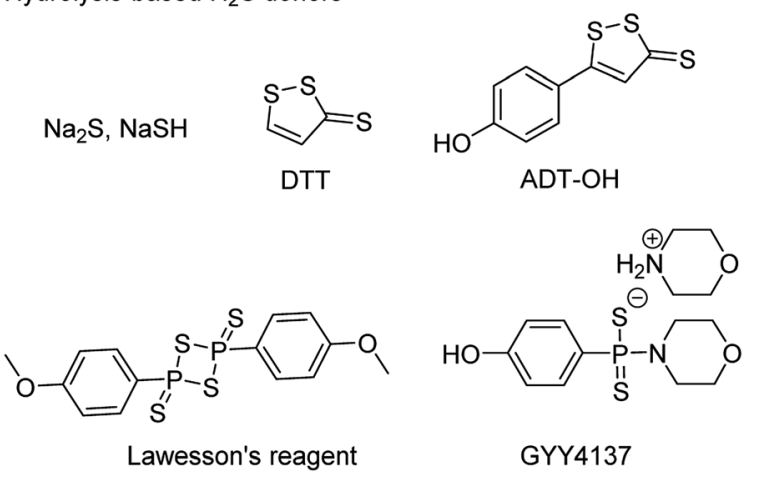

b) Thiol activated $\mathrm{H}_{2} \mathrm{~S}$ donors<smiles>[R]C(=O)NSC([R])=O</smiles><smiles>[R]C(=O)SSC([R])=O</smiles><smiles>[R]C(N)=S</smiles><smiles>[R]C(N)C(=O)S</smiles><smiles></smiles><smiles>[R]C(=O)SSC(C)(C)[C@H](NC(=O)[OH2+])C(N)=O</smiles>

c) $\mathrm{pH}$ controlled $\mathrm{H}_{2} \mathrm{~S}$ donor<smiles>O=C(CNP([O-])(=S)c1ccccc1)O[Ga]</smiles>

Fig. 4 Representative examples of chemically activated $\mathrm{H}_{2} \mathrm{~S}$ donors.

irradiation with UV light, compounds decomposed to release $\mathrm{H}_{2} \mathrm{~S}^{73}$ Nakagawa and co-workers also contributed to the field by reporting thioether based scaffolds which are activated by UV light to produce $\mathrm{H}_{2} \mathrm{~S} .{ }^{74}$ However, the toxicity caused by UV light limits the use of these donors in a physiological system. Visible light driven $\mathrm{H}_{2} \mathrm{~S}$ donors were reported in the year 2013 by You and co-workers where 1,3-diphenylisobenzothiophenone (DPBT) reacts with singlet oxygen to produce unstable endoperoxide which promptly undergoes fragmentation to give $\mathrm{H}_{2} \mathrm{~S} .{ }^{75}$ A very recent report of visible light activated $\mathrm{H}_{2} \mathrm{~S}$ donor with real time monitoring has been reported by Singh and coworkers. $^{76}$ Connal and co-workers also reported thiobenzaldehyde based $\mathrm{H}_{2} \mathrm{~S}$ donors which are activated by light of $355 \mathrm{~nm}$ (Fig. 5a). ${ }^{77}$

In order to attain better and efficient release of $\mathrm{H}_{2} \mathrm{~S}$ in a mammalian system Binghe Wang and co-workers in 2016 reported esterase sensitive $\mathrm{H}_{2} \mathrm{~S}$ donors (Fig. $5 \mathrm{~b}$ ). ${ }^{78}$ The donors were found to attenuate the levels of pro-inflammatory cytokine TNF- $\alpha$ by releasing $\mathrm{H}_{2} \mathrm{~S}$. The first ever report of bacteria targeted delivery of $\mathrm{H}_{2} \mathrm{~S}$ came in 2017 by Chakrapani and co-workers where they report nitroreductase (NTR) activated $\mathrm{H}_{2} \mathrm{~S}$ donors for selectively generating $\mathrm{H}_{2} \mathrm{~S}$ in bacteria (Fig. 5b). ${ }^{79}$ The donors were used to study the role of $\mathrm{H}_{2} \mathrm{~S}$ in antibiotic resistance in patient-derived uropathogenic strains of Escherichia coli ( $E$. coli). They find that modulating $\mathrm{H}_{2} \mathrm{~S}$ levels has a tremendous 
a) Light activated $\mathrm{H}_{2} \mathrm{~S}$ donors<smiles>[R]C([R2])(SCc1ccccc1[N+](=O)[O-])SCc1ccccc1[N+](=O)[O-]</smiles><smiles>CC(C)SCC(C)(C(=O)O)c1cccc(C(=O)c2ccccc2)c1</smiles>

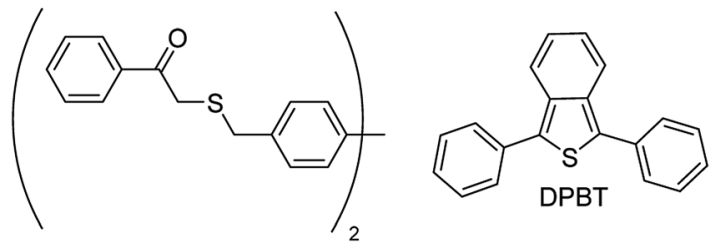

b) Enzyme activated $\mathrm{H}_{2} \mathrm{~S}$ donor<smiles>[R]C(=O)Oc1cc(C)cc(C)c1C(C)(C)CC(=O)S</smiles><smiles>[R]C([R])(SCc1ccc([N+](=O)[O-])cc1)SCc1ccc([N+](=O)[O-])cc1</smiles>

Fig. 5 (a) Light activated $\mathrm{H}_{2} \mathrm{~S}$ donors (b) $\mathrm{H}_{2} \mathrm{~S}$ donors triggered by enzyme.

impact on the bacterium's ability to counter stress inducted by an antibiotic. In particular, they find that multi-drug resistant strains of this pathogen could be sensitized to the antibiotic that they were previously resistant to by inhibiting biosynthesis of hydrogen sulfide. The resistance was restored by supplementing the bacterium with their donor. This study, with support from previous data, provided a significant advancement in our understanding of the role of hydrogen sulfide in antibiotic stress reduction and drug resistance. ${ }^{\mathbf{8 0}}$

Although the rate of hydrolysis of COS in water is extremely slow $2.2 \times 10^{-5} \mathrm{~s}^{-1}$, it readily hydrolyses in the presence of carbonic anhydrase (CA). ${ }^{\mathbf{8 1 , 8 2}}$ The rate of COS hydrolysis by carbonyl sulfide hydrolase (COSase) obtained from $T$. thioparus strain TH1115 is reported as $58 \mathrm{~s}^{-1} \cdot{ }^{83} \mathrm{CA}$ obtained from bovine erythrocytes hydrolyses COS at the rate of $1.82 \mathrm{~s}^{-1}$ to give $\mathrm{H}_{2} \mathrm{~S}$ and $\mathrm{CO}_{2} \cdot{ }^{84} \mathrm{CA}$ is a ubiquitous enzyme and this enzyme would therefore be available to hydrolyse COS within cells to produce hydrogen sulfide (Scheme 1). This strategy was employed to design a new class of $\mathrm{H}_{2} \mathrm{~S}$ donors based on initial release of COS.

Pluth and co-workers in 2016 reported O-alkyl based thiocarbamates with azide group as a trigger. The azide group was reduced in the presence of $\mathrm{H}_{2} \mathrm{~S}$ resulting in analyte consumption which perturbed the homeostasis. Upon activation a selfimmolative decomposition of thiocarbamates led to the formation of COS which was further hydrolysed by CA to give back $\mathrm{H}_{2} \mathrm{~S}$ (Scheme 2a). ${ }^{84}$ Although it was the first report of triggerable COS donors, the activation required consumption of $\mathrm{H}_{2} \mathrm{~S}$ and therefore this strategy is mainly useful for detection of hydrogen sulfide.

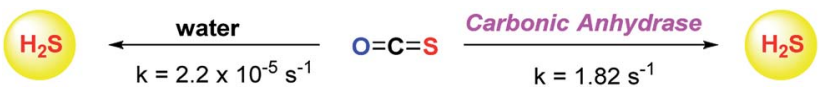

Scheme 1 Hydrolysis of $\mathrm{COS}$ to $\mathrm{H}_{2} \mathrm{~S}$.
Later in the year, Zhao et al. from the same group reported $\mathrm{COS} / \mathrm{H}_{2} \mathrm{~S}$ donors which are activated by reactive oxygen and nitrogen species (RONS). Compounds were found to exhibit protective effects against $\mathrm{H}_{2} \mathrm{O}_{2}$ induced oxidative stress (Scheme 2b). ${ }^{85} \mathrm{~A}$ follow up on this report was published wherein the core structure of thiocarbamate scaffold was modified to attain different derivatives for achieving tunable release of $\mathrm{H}_{2} \mathrm{~S}$. However, in the case of electron withdrawing groups the donors were found to be unstable and resulted in isothiocyanate formation. Isothiocyanates being electron deficient can readily react with biological nucleophiles (thiols and amines) and therefore can be toxic.

One of the derivatives led to carbon disulfide formation which showed reduced yields of $\mathrm{H}_{2} \mathrm{~S}$ due to slow rate of hydrolysis. ${ }^{86}$ Although its hydrolysis in cells is possible, carbon disulfide is toxic to the cells and prolonged exposure of cells to $\mathrm{CS}_{2}$ is not desirable. Hence, there is a need to have donors with broad range of tunability and less toxicity. Pluth and co-workers also reported COS donors using bio-orthogonal methods. The thiocarbamate moiety was attached with cyclooctene which upon reaction with tetrazine through inverse electron demand Diels-Alder click (IEDDA) reaction release COS (Scheme 2c). The donors were found to be incompatible with biological systems and therefore could not be used for further applications. ${ }^{87}$ Polymeric COS donors were reported by Matson and group in 2016 wherein they investigated $N$-thiocarboxyanhydride (NTA) based scaffolds which upon reaction with biological nucleophiles result in COS release (Fig. 6d). Both small molecule (NTA1) and polymer (pNTA1) were tested for their ability to produce $\mathrm{H}_{2} \mathrm{~S}$ via COS release. NTA1 was found to promote cell proliferation. ${ }^{88}$

COS based strategy to release $\mathrm{H}_{2} \mathrm{~S}$ was further explored by Chauhan and co-workers where they report esterase enzyme activated S-alkyl carbonothioates and carbamothioates as COS/ $\mathrm{H}_{2} \mathrm{~S}$ donors. The rate of $\mathrm{H}_{2} \mathrm{~S}$ release from these donors was moderately dependent on the basicity of the leaving group amine. Being well tolerated by cells, the donors can be used for further applications (Scheme 3). ${ }^{89} \mathrm{~A}$ similar strategy was reported by Pluth and co-workers to release COS upon activation by esterase. The compounds were found to be toxic at $10 \mu \mathrm{M}$ concentration and therefore could not be employed for biological studies. However, the toxicity was attributed to the reduced cellular respiration and ATP synthesis by inhibition of cytochrome $c$ oxidase in the mitochondrial respiratory chain. ${ }^{\mathbf{9 0}}$

The scope of the $\mathrm{COS} / \mathrm{H}_{2} \mathrm{~S}$ donors was further expanded by the introduction of light activated COS donors. Pluth and coworkers reported UV light activated $\mathrm{COS} / \mathrm{H}_{2} \mathrm{~S}$ donors (Fig. 6). ${ }^{91}$ But due to the toxic effects of UV light these donors may not provide broad applicability.

Visible light activated $\mathrm{COS} / \mathrm{H}_{2} \mathrm{~S}$ donors reported by Sharma et al. overcame this limitation and the donor $\mathrm{BDP}-\mathrm{H}_{2} \mathrm{~S}$ reported by them works by activation by light at $480 \mathrm{~nm}$ (Fig. 6). The authors find that upon activation, an enhancement in fluorescence signal occurred. This serves as a convenient signal to infer activation. BDP- $\mathrm{H}_{2} \mathrm{~S}$ was well tolerated by cells and may be useful for studying $\mathrm{H}_{2} \mathrm{~S}$ related cell signaling. ${ }^{91}$ However, the wavelength of activation needs to be further increased as the 
(a) Azide based COS donors

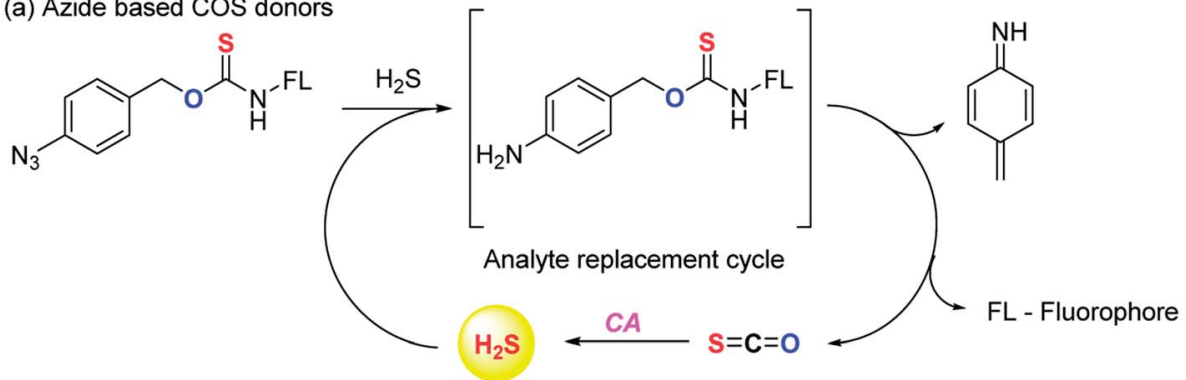

(b) ROS activated COS donors

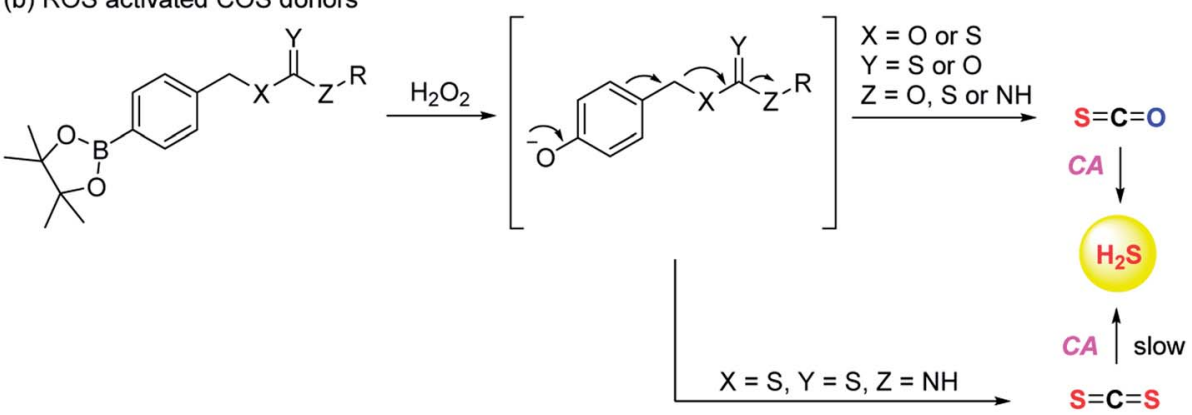

(c) Bio-orthogonal COS donors

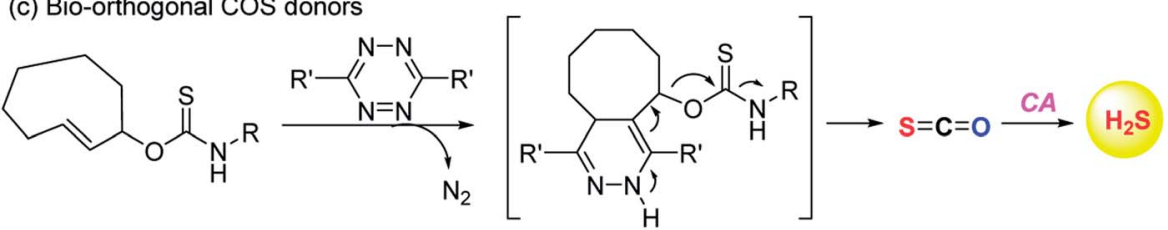

(d) Nucleophile activated $\mathrm{COS} / \mathrm{H}_{2} \mathrm{~S}$ donor

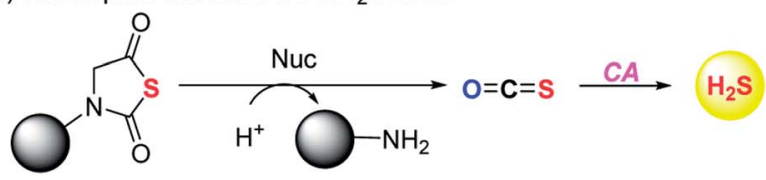

Scheme 2 Chemically triggered COS donors.

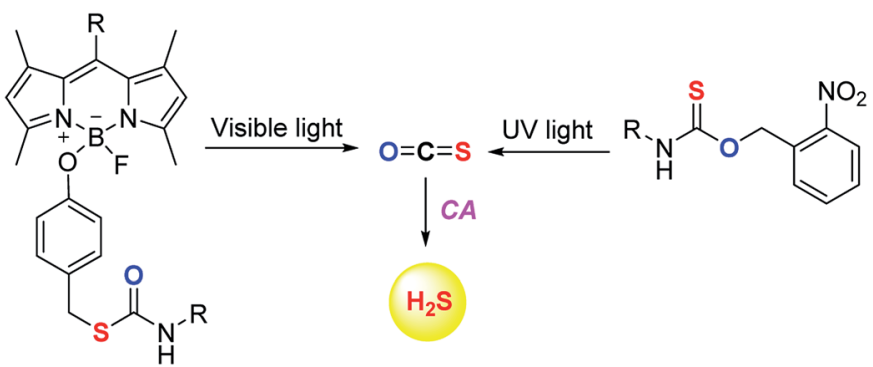

Fig. 6 Light activated COS donors.

light of $\sim 450-500 \mathrm{~nm}$ also induces oxidative stress, albeit at substantially lower levels when compared with UV light.92 Also, the aqueous solubility of these compounds was diminished and may be a major impediment to the wide use of this compound.

Although the field of $\mathrm{H}_{2} \mathrm{~S}$ donors has made significant advancements over the past two decades, there is still a need to have better donors for studying precise biological effects of the gas. Also, the donors should be benign with minimal side- effects to explore the therapeutic potential of this gasotransmitter. Further work in this area should focus on greater efficiency of release with improved triggers. Also, the lack of reliable in vivo studies on most of these donor compounds makes evaluation of their therapeutic potential difficult.

Lastly, achieving tunability of $\mathrm{H}_{2} \mathrm{~S}$ release from donors is a major challenge. Since the rate of generation of hydrogen sulfide has been previously shown to have major impact on the observed biological end-point, it is therefore important to develop donors with a good structural handle to modulate release rates. A number of polymer or materials-based methods for achieving this goal are in the literature. ${ }^{93-95}$ The rates of release can be typically varied from a few seconds to minutes to hours. However, the use of polymers is associated with issues such as toxicity, cell-permeability etc.

While these methods are useful, it is highly desirable to be able to modulate release rates using small molecules. Chauhan and co-workers have some preliminary evidence for the dependence of $\mathrm{COS} / \mathrm{H}_{2} \mathrm{~S}$ release rates on the amine. Thus, this 

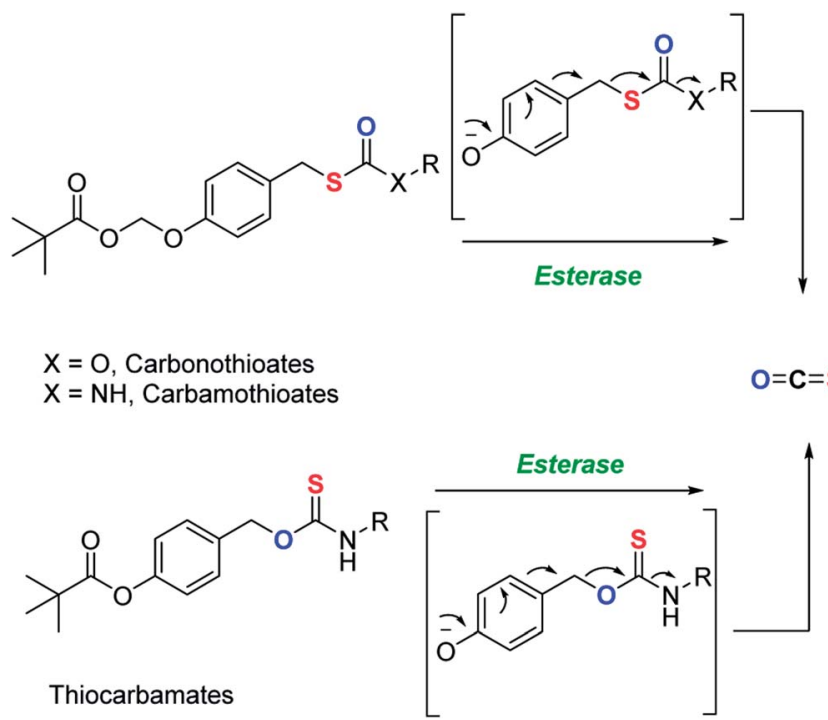

Scheme 3 Esterase activated COS donors.

problem needs to be addressed in future in order to better exploit the translational potential of this gas. A number of research groups including ours are working on solving this issue and it is anticipated that this problem will be adequately addressed in the near future.

\section{Perthiols}

Perthiols or persulfides (RSSH) form another class of reactive sulfur species with sulfur oxidation state -1 each. Protein Ssulfhydration is an oxidative post translational modification of cysteine residues wherein the cysteine thiol (RSH) gets modified to a persulfide intermediate (RSSH). ${ }^{11}$ This burgeoning area of research has gained considerable attention in the recent years because of its potential role as a mediator in $\mathrm{H}_{2} \mathrm{~S}$ signaling pathways. ${ }^{2,96,97}$ Several protein targets have been identified to be S-sulfhydrated with various therapeutic outcomes but the role of $\mathrm{H}_{2} \mathrm{~S}$ and the mechanism by which it carries out this modification remains largely elusive and warrants further attention. ${ }^{98,99}$ Since $\mathrm{H}_{2} \mathrm{~S}$ cannot modify protein thiols directly due to redox constraints, it is considered to react with oxidized cysteine residues. However, recent studies indicate that other reactive sulfur species like polysulfides and persulfides are more potent S-sulfhydrating agents. ${ }^{100-104}$ The biogenesis of persulfides in mammals involve sulfurtransferases like 3-mercaptopyruvate sulfurtransferase (3-MST), human rhodanese and thiosulfate sulfurtransferase (TST), which form a transient persulfide intermediate in the active site cysteine, subsequently S-sulfhydrating a protein. ${ }^{2}$ Low molecular weight persulfides like CysSSH, on the other hand are biosynthesized by $\mathrm{H}_{2} \mathrm{~S}$ producing transsulfuration pathway enzymes like CSE and CBS using cysteine as a substrate. ${ }^{100,105,106}$ Hence, as the biochemistry of persulfides begins to unravel, whether $\mathrm{H}_{2} \mathrm{~S}$ is the actual signaling molecule or just a product of persulfide degradation is being debated. To better understand the nuances of these reactive sulfur species, there is a need to develop robust detection techniques and precursors or prodrugs that can efficiently generate these species in situ. In this regard, not much progress has been made in the field of persulfides, in contrast to $\mathrm{H}_{2} \mathrm{~S}$ mainly due to the challenges associated with it. While there have been significant advances in developing methods for reliable detection of S-sulfhydration, ${ }^{1,107-112}$ there are limited number of donors available that can generate persulfides in situ in a controlled manner.

The first report for the preparation of Low molecular weight persulfides or 'hydrodisulfides' date back to 1954 by Horst and Gerwalt. ${ }^{13}$ Following this there have been intermittent reports on the preparation of few isolated persulfides like ethyl, tertbutyl, benzyl, diphenylmethyl, trityl and adamantyl persulfides providing snippets of information about the chemical properties and reactivity of persulfides (Fig. 7). ${ }^{96,97}$ Trityl persulfides are relatively stable owing to its steric bulk, for it to be characterized by NMR, XRD, IR and Raman. ${ }^{114}$ Similarly, adamantyl persulfides can be stored indefinitely under inert conditions and at $-20{ }^{\circ} \mathrm{C} .{ }^{115,116}$ However, the chemical biology of these persulfides and their potency to S-sulfhydrate proteins were not reported. It is likely that this is due to their poor aqueous

(a)

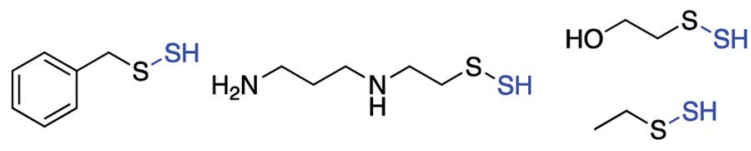

(b)

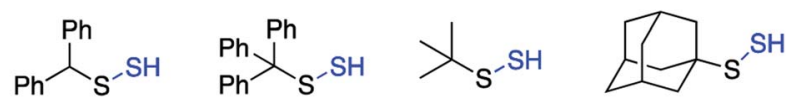

Fig. 7 Low molecular weight (a) unhindered persulfides (b) hindered persulfides. 
solubility and perhaps diminished rates of persulfidation due to steric hindrance.

In order to unravel the complex biochemistry of persulfides, small molecule perthiols like cysteine and glutathione persulfides were prepared in situ by the reaction of their disulfide counterpart with $\mathrm{H}_{2} \mathrm{~S}{ }^{117-120}$ The reaction being reversible in nature suffer from obvious drawbacks. To address this, a small molecule persulfide precursor was developed by Erwan Galardon and Isabelle Artaud that spontaneously rearranges by an intramolecular acyl transfer in aqueous buffer $(\mathrm{pH}>6)$ generating the persulfide in situ. The rate of persulfide formation was found to be $\mathrm{pH}$ dependant and maximum rate was observed under basic condition (Scheme 4). ${ }^{121}$

Ming Xian and co-workers have also developed a biomimetic persulfidation precursor, i.e. a functional 9-fluorenylmethyl disulfide (FmSSPy-A) for the formation of persulfides from the corresponding thiols. These disulfide precursors efficiently react with various small molecule thiols or protein thiols to form a base sensitive disulfide RSS-Fm adduct, which upon treatment with a suitable base generates the persulfide (Scheme $5 \mathrm{a}$ ). The authors have used DBU as the base and have demonstrated the reactivity of persulfides towards various electrophiles. Using BSA as a model protein, DBU as a base and monobromobimane $(\mathrm{mBBr})$ /iodoacetamide (IAM) as the persulfide blocking reagent, the authors have demonstrated the efficiency of their method to S-sulfhydrate protein thiols. ${ }^{122}$ Although this method provides an excellent platform to explore the chemical biology of persulfides, the use of chemical reagents like DBU limits its utility in biological systems.

Ming Xian and co-workers have also recently reported another facile method for generation of persulfide species using cyclic acyl disulfides (Scheme 5b). Acyclic acyl disulfides have been frequently used as precursors for synthesis of low molecular weight persulfides. However, cyclic acyl disulfides as potential persulfide donors had not been considered. Two five

(a)

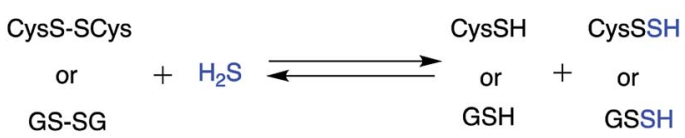

(b)

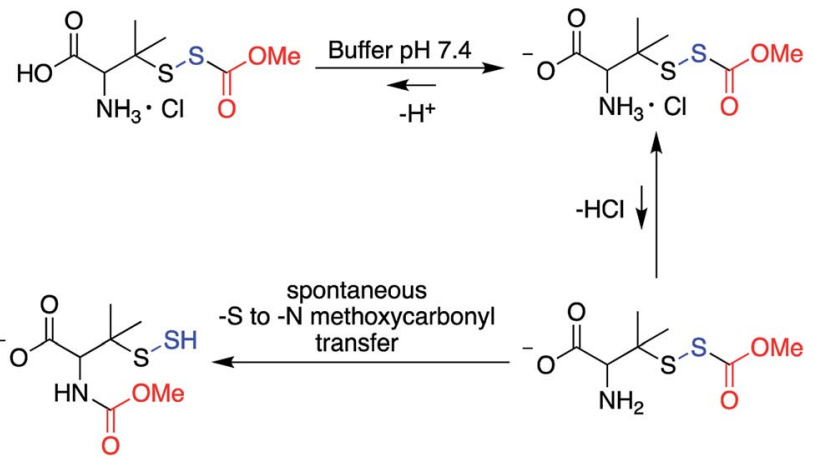

Scheme 4 (a) Generation of small molecule persulfides by reaction of $\mathrm{H}_{2} \mathrm{~S}$ with their corresponding disulfides (b) persulfide analogue of the nitrosothiol $S$-nitrosoacetylpenicillamine (SNAP). membered ring substrates, dithiolane and benzodithiolane was reported which was made to react with physiologically significant nucleophiles like amines and thiols. Reaction of the dithiolane derivative with $n$ - $\mathrm{BuNH}_{2}$ resulted in the formation of a polysulfide intermediate, presumably through the formation of an unstable persulfide intermediate. The intermediate was subsequently trapped using iodoacetamide, a commonly used thiol blocking agent. However, its reaction with thiols ( $n$-BuSH) appeared to be complicated. The authors have proposed two plausible mechanisms for their observation, wherein the thiol can attack either the carbonyl or the sulfur next to it. On the other hand, the benzodithiolane proved to be more stable than the former with sluggish reactivity towards amines and no reactivity with thiols. $^{123}$ Even though the persulfideiodoacetamide adduct and $\mathrm{H}_{2} \mathrm{~S}$ generation from these compounds in presence of cysteine or glutathione is a testament to the generation of a perthiol species, further validation under physiological conditions was not carried out.

Recently, Binghe Wang and co-workers have developed small molecule prodrugs for persulfide generation while demonstrating their therapeutic potential in murine model of myocardial infarction reperfusion (MI/R) injury. These esterase sensitive prodrugs would self-immolate in presence of the widely prevalent esterase enzyme to generate a perthiol species and the corresponding aldehyde as a by-product (Scheme 5c). The authors have systematically evaluated the formation of persulfide by trapping it with 2,4-dinitrofluorobenzene (DNFB) and $S$-methyl methanethiosulfonate (MMTS). The varying ester functionalities further provided a scope for tuning the release kinetics of persulfides. ${ }^{124}$ We anticipate that these prodrugs will serve as vital tools to decipher biological mechanisms of persulfides.

Hydrodisulfide or hydrogen persulfide $\left(\mathrm{H}_{2} \mathrm{~S}_{2}\right)$ has been considered as an important player in sulfur signaling. However, due to its rapid decomposition to produce $\mathrm{H}_{2} \mathrm{~S}$ and elemental sulfur, it is difficult to differentiate its effects from $\mathrm{H}_{2} \mathrm{~S}$. Nevertheless, an enzyme activated prodrug for $\mathrm{H}_{2} \mathrm{~S}_{2}$ has been developed by Binghe Wang and co-workers. The design employs a tri-methyl lock based system masked by ester and phosphate functionalities, such that upon activation by esterase or alkaline phosphatase $\mathrm{H}_{2} \mathrm{~S}_{2}$ is generated after cyclization (Scheme $5 \mathrm{~d}$ ). Significant levels of persulfidation was observed in GAPDH when treated with the $\mathrm{H}_{2} \mathrm{~S}_{2}$ prodrug. In contrast, conforming with earlier reports $\mathrm{H}_{2} \mathrm{~S}$ alone failed to induce persulfidation but only in presence of $\mathrm{H}_{2} \mathrm{O}_{2}$. However, polysulfides formed from $\mathrm{H}_{2} \mathrm{~S}_{2}$ degradation might be the actual persulfidating agent and not $\mathrm{H}_{2} \mathrm{~S}_{2}$ itself. ${ }^{125}$ These handful of persulfide prodrugs offer distinct advantages to study the intricate biochemistry of persulfides and have initiated an area that will command further attention in future.

\section{Sulfur dioxide}

Sulfur dioxide has been extensively used in organic synthesis (Fig. 8) and needless to say, it is a versatile reagent. ${ }^{126,127}$ Sulfur dioxide is generated during burning of fossil fuels, volcanic eruptions and other industrial processes. Once released in the 


\section{Chemically activated persulfide prodrugs}

(a) 9-Fluorenylmethyl Disulfides as biomimetic precursors for persulfides
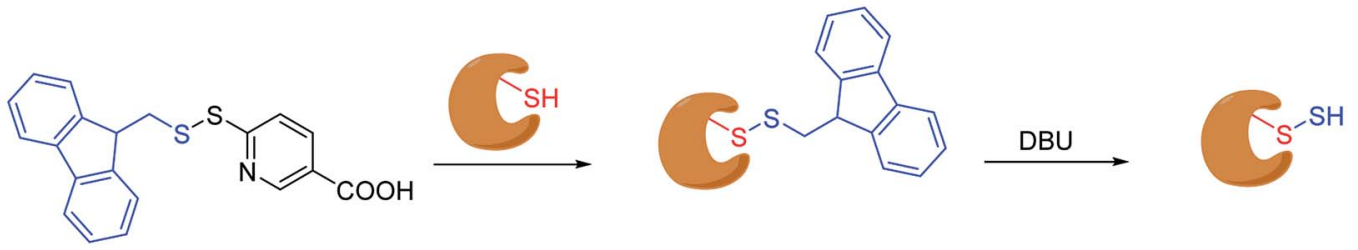

(b) Cyclic acyl disulfides as precursors for persulfides
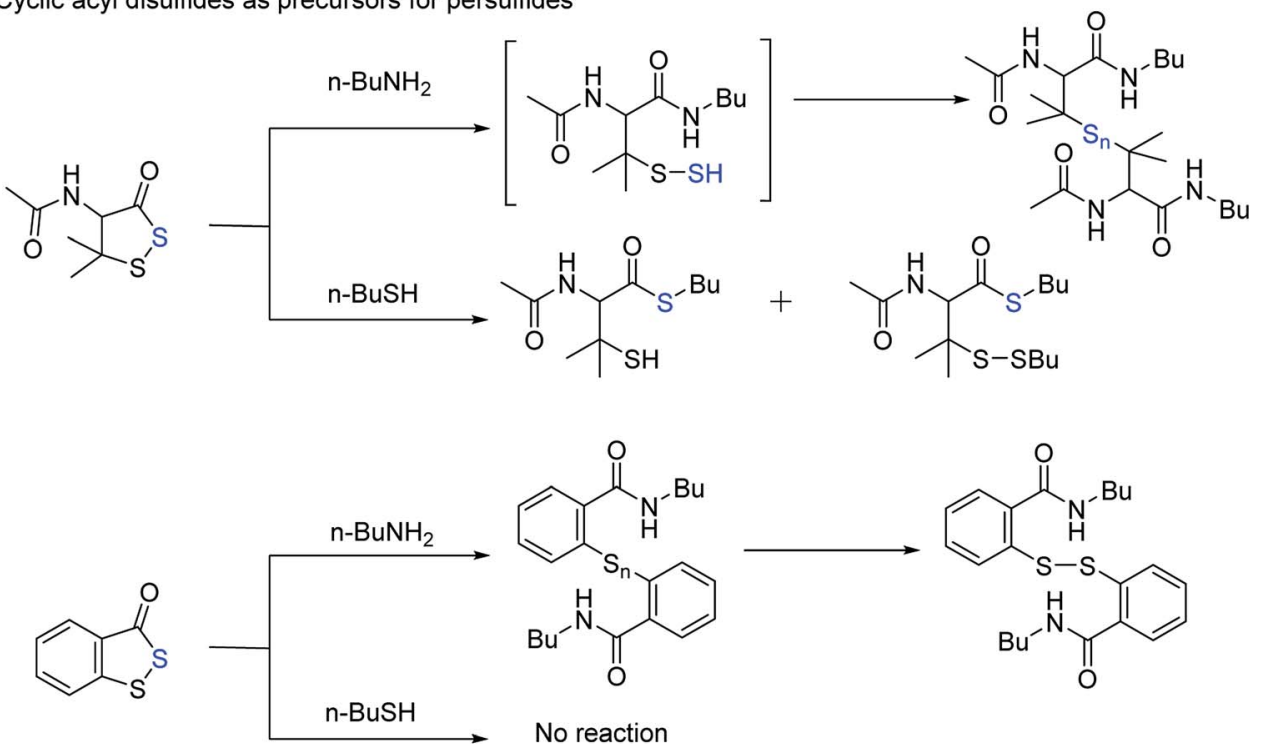

\section{Enzyme activated persulfide prodrugs}

(c) Esterase sensitive prodrugs of persulfides

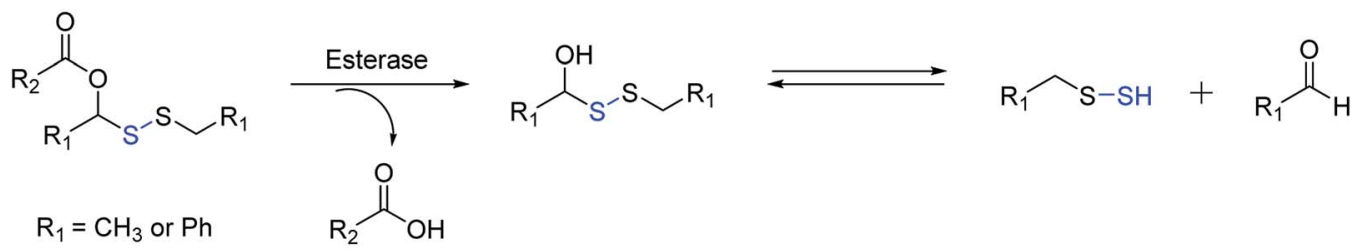

(d) Prodrugs of hydrogen persulfide

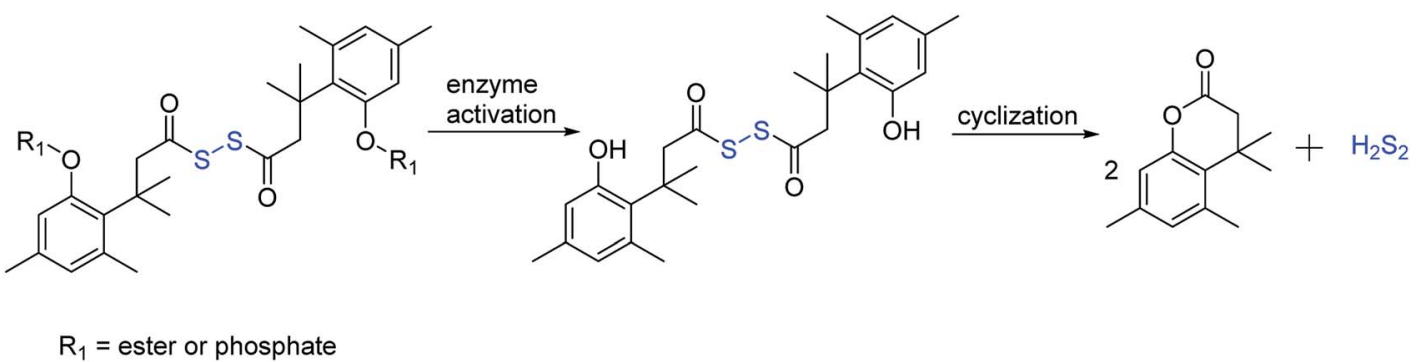

Scheme 5 Prodrug strategies for the generation of persulfides (a) biomimetic prescussors for the generation of persulfides in presence of a base such as DBU (1,8-diazabicyclo(5.4.0)undec-7-ene). (b) Cyclic acyl disulfides as precursors for persulfides in presence of biological nucleophiles (c) prodrugs of persulfides activated by the widely prevalent esterase enzyme (d) trimethyl based prodrugs for hydrogen persulfides, activated by esterase and alkaline phosphatase. 


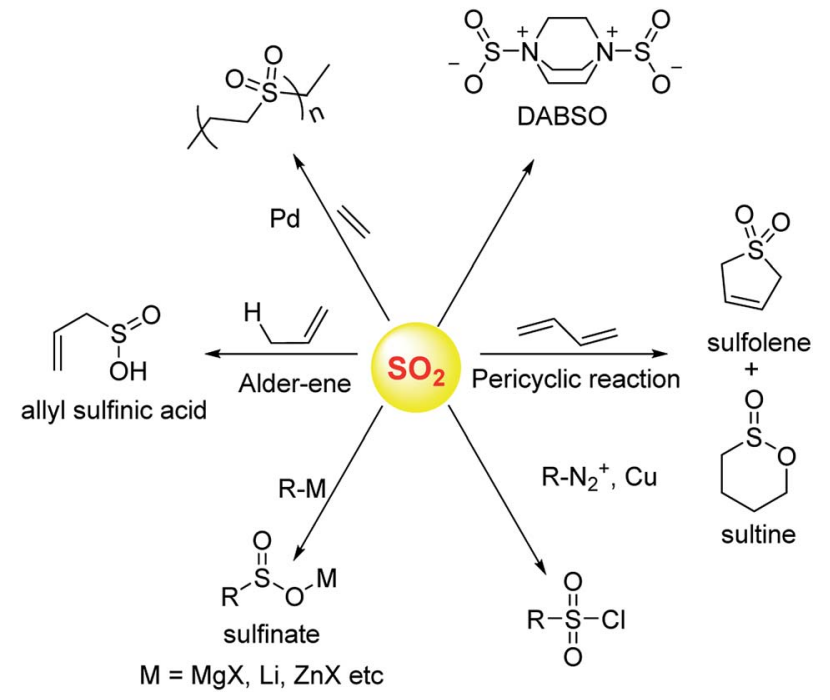

Fig. 8 Selected synthetic transformations of sulfur dioxide.

atmosphere, this gas can get further converted to acidic species of higher oxidation states including sulfuric acid. This, in part, leads to acidification of the atmosphere and contributes to acid rain. In addition, several respiratory illnesses can be traced back to excessive amounts of this gas in the environment.

Once generated within cells, sulfur dioxide and its hydrated forms bisulfite and sulfite can interact with various biological macromolecules..$^{33,128,129}$ Due to its propensity to get oxidized, sulfite can be classified as an antioxidant. The molybdopterin containing enzyme sulfite oxidase catalyzes this reaction. $\mathrm{SO}_{2}$ reacts with cysteine-containing proteins to produce S-sulfites $\left(\mathrm{RS}^{-} \mathrm{SO}_{3}{ }^{-}\right)$, presumably by reaction of a disulfide with sulfite. ${ }^{30-132}$ Autoxidation of sulfite catalyzed by metal ions can generate highly reactive radical species which are known to damage DNA.

Donors of sulfur dioxide are envisaged as tools to study the precise biological effects of this gas as well as possibly exploiting its therapeutic potential. Although sulfur dioxide is used fairly well in organic synthesis, being a gas is somewhat cumbersome for use. Recent efforts to make caged sulfur dioxide donors for organic synthesis has been reviewed elsewhere. ${ }^{126,127,133}$ An example is DABSO,${ }^{134}$ which is an adduct of $\mathrm{DABCO}$ and sulfur dioxide and is used to generate this gas in situ. The compounds discussed herein have been shown to produce $\mathrm{SO}_{2}$ under biologically relevant conditions.

In order to generate $\mathrm{SO}_{2}$, a sulfone or a sulfonate ester are good starting points (Scheme 6). The first report in the literature describing the anti-bacterial effects of sulfur dioxide donors was from our laboratory in $2012 . .^{135}$ The authors used a 2,4-dinitrophenylsulfonamide as the major functional group for generating sulfur dioxide. ${ }^{136}$ This functional group has been used as a protective group in organic synthesis previously and is deprotected by thiols. ${ }^{136}$ Using this observation as the cue, and since cellular thiols occur in large concentrations, Malwal and co-workers demonstrated the suitability of this series of compounds as sources of sulfur dioxide (Scheme 7). They find that the rate of sulfur dioxide generation was dependent on the nature of the amine. ${ }^{137}$ The more basic the amine was, the faster was the sulfur dioxide generation. Thus, simple structural modifications that affected the basicity of the amine formed the basis for modulating release rates.

The authors evaluated the potential for these compounds to inhibit bacterial growth and they found that, among closely related compounds, the propensity to inhibit mycobacterial growth was dependent on the rate of sulfur dioxide generation. ${ }^{135,137}$ The lead compound was found to have low micromolar inhibitory potency against Mycobacterium tuberculosis, the causative agent of tuberculosis, a disease that affects millions each year. This series of compounds was evaluated for the broad-spectrum antibacterial activity and it was found that the benzylamine derivative, which had potent antimycobacterial activity had no inhibitory activity against other Gram-positive as well as Gram-negative bacteria. A recent study on the effects of sulfur dioxide on tuberculosis occurrence in human populations was conducted. ${ }^{138}$ The authors found protective effects of this gas when patients were exposed to lowlevel ambient sulfur dioxide against TB.

Pardeshi and co-workers did a series of structural modifications that led to improved anti-bacterial properties, but only against Gram-positive pathogens. ${ }^{139}$ The structural modifications resulted in compounds with good inhibitory activity against drug-resistant strains of Staphylococcus aureus.

The benzylamine derivative has been used by several groups as a positive control for sulfur dioxide/sulfite generation. ${ }^{140}$ This compound thus reliably generates sulfur dioxide upon permeation into mammalian cells as well. Together, these compounds are useful as tools to generate sulfur dioxide and provide the scope for tuneable release of this gas. They display anti-bacterial properties and will need further evaluation for potential as therapeutic agents.

Sulfones have been reported to undergo cycloreversion to generation sulfur dioxide (Scheme 8). ${ }^{141,142}$ Typically elevated temperatures are required for this reaction. This strategy has been modified by Binghe Wang and co-workers to generate a highly reactive sulfone intermediate in situ (Scheme 9). The strategy followed was a "click and release" one, where a cycloaddition between and strained alkyne and a diene was used (Scheme 9) ${ }^{143}$ This reaction was carried out with two independent reactants and a follow-up on this work had an intramolecular reaction. ${ }^{144}$ The latter strategy has been used to tune release of sulfur dioxide from a few minutes to days.

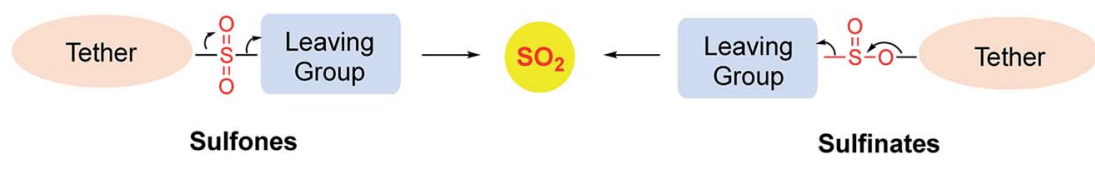

Scheme 6 General strategies for $\mathrm{SO}_{2}$ generation. 


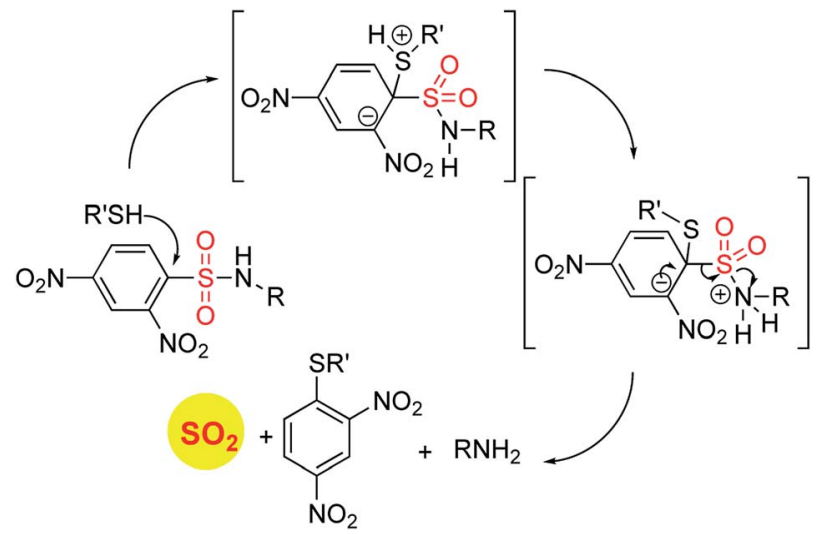

Scheme 7 Thiol activated $\mathrm{SO}_{2}$ donors.

Binghe Wang and co-workers recently reported a sulfone that was a candidate for Julia olefination reaction (Scheme 12). ${ }^{\mathbf{1 4 5}}$ They modified this substrate to be triggered by esterase to generate and olefin and sulfur dioxide. Using a latent fluorophore that reacts with sulfite to become fluorescent, the donor was found to permeate cells to generate sulfur dioxide. The authors also show that the half-life of release of sulfur dioxide could be modulated by changing the substituent. Together, this donor may find wide use for cellular studies to interrogate the chemical biology of sulfur dioxide.
Similarly, sulfones can also generate sulfur dioxide after exposure to light. Malwal and co-workers have demonstrated that benzosulfones can be irradiated with UV light to produce sulfur dioxide in pH 7.4 buffer. ${ }^{146}$ While this method allows for triggerable sulfur dioxide generation, the wavelength and intensity of light used is not entirely compatible for biological studies. Uchida and co-workers have reported a closed ring isomer of diaryl ethene bearing a sulfone group as a masked $\mathrm{SO}_{2}$ donor. ${ }^{147}$ In presence of visible light, the closed ring isomer gets converted into its open ring form but does not generate $\mathrm{SO}_{2}$ and also found to be stable at $70{ }^{\circ} \mathrm{C}$. However, upon exposure to UV light, both the isomers exist in equilibrium and the open ring form efficiently generates $\mathrm{SO}_{2}$.

Sulfinate esters are also candidates for sulfur dioxide generation. A cycloreversion strategy was reported by Malwal and coworkers. ${ }^{\mathbf{1 4 8}}$ Here, benzosultines were synthesized and these compounds were found to undergo retro Diels-Alder reaction to produce sulfur dioxide (Scheme 10a). A Hammett relationship study was carried out and the dependence of the rates of $\mathrm{SO}_{2}$ release on substituents on the carbon bearing the sulfinate ester was determined. A moderate electronic effect $(\rho=-0.6)$ was found and the range of half-lives for $\mathrm{SO}_{2}$ generation was 10$68 \mathrm{~min}$. A detailed computational investigation of the release mechanism was carried out and was found to be consistent with experimental data. This study showed that modulating the

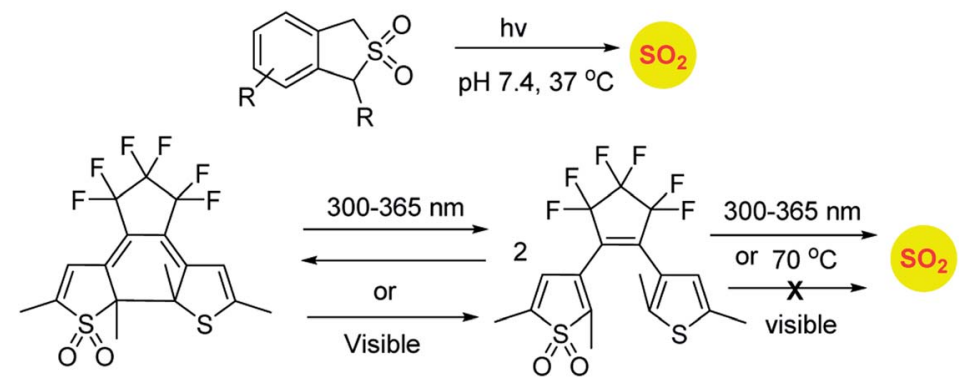

Scheme 8 Photolabile $\mathrm{SO}_{2}$ donors.
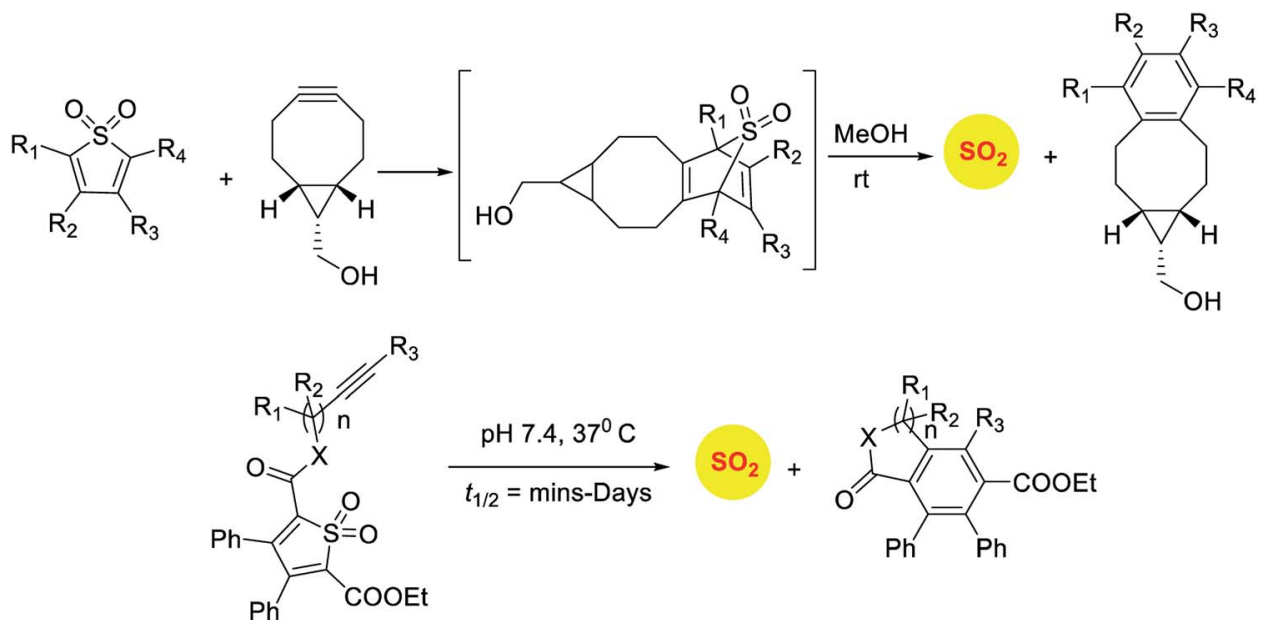

Scheme 9 Click and release strategies for sulfur dioxide generation. 
(a)<smiles>[X]c1cccc(C2OS(=O)Cc3ccccc32)c1</smiles>

(b)

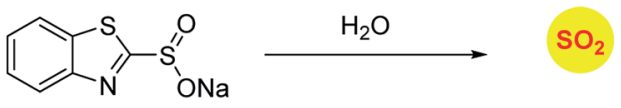

Scheme 10 Sulfinate based $\mathrm{SO}_{2}$ donors.

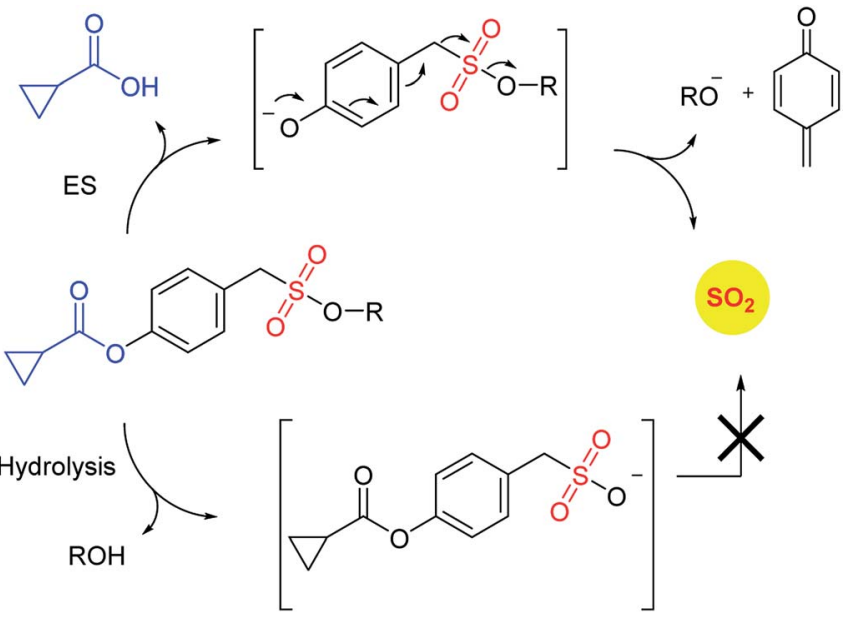

Scheme 11 Esterase activated $\mathrm{SO}_{2}$ donors.

electronic environment around the sulfonate functional group may have an effect on release of sulfur dioxide.

Ming Xian and co-workers have developed benzothiazole sulfonate salt, a new sulfonate ester-based donor that undergoes hydrolysis in buffer to produce sulfur dioxide. ${ }^{149}$ This compound is water-soluble and release sulfur dioxide over several hours (Scheme 10b). They studied this donor's vasorelaxation properties as compared to the authentic $\mathrm{SO}_{2}$ gas solutions and found that the donor compared well with $\mathrm{SO}_{2}$ in this respect. This compound showed $\mathrm{pH}$-dependent release and this study is a major advancement in the use of $\mathrm{SO}_{2}$ as a vasorelaxant.
Recently, Pardeshi and co-workers have reported a sulfonate ester that undergoes self-immolation in the presence of esterase to produce sulfur dioxide and an alcohol (Scheme 11). ${ }^{150}$ The sulfonate esters are modelled on carbonates, which are frequently used as linkers in prodrugs. A large majority of the sulfonates evaluated were found to generate sulfur dioxide. Certain donors which are derived from aliphatic alcohols were found to hydrolyze even in the absence of esterase. The best donors were found to permeate cells to generate sulfite. Thus, this series of compounds are potentially useful for studying the chemical biology of sulfur dioxide.

\section{Summary and outlook}

A better understanding of the precise physiological roles and targets for reactive sulfur species is not only of academic interest but also may have numerous applications. A key aspect of gaining this knowledge is to generate in a controlled manner, reactive sulfur species. This has been an interest in our lab as well as in several laboratories globally. While numerous techniques are presently available, this is yet an emerging field of study. Some donors offer promise and may emerge as routine tools for redox biologists. The major challenge is to translate these interesting activities into therapy. Little work has been done in this regard and the next generation of studies will focus on this.

In parallel, the development of tools to detect each of these reactive species has matured and robust methodologies are in place. However, no single methodology can unambiguously detect and quantify these reactive sulfur species, which remains an unsolved problem. Lastly, the work done towards dissipation or selective inhibition of biosynthesis is yet in its infancy. These technologies may hold the key for accurate interrogation of the physiological effects of these species. Tools that can reliably inhibit the biosynthesis can be used in conjunction with small molecules that can generate these species to study the effects of modulating the levels of reactive sulfur species within cells. In the past three decades, reactive nitrogen species such as nitric oxide (NO), ${ }^{151}$ nitroxyl ${ }^{5,142}$ and peroxynitrite ${ }^{152,153}$ have been systematically studied and this is, in part, due to the ready availability of small molecules that dissociate to generate these species. ${ }^{154-158}$

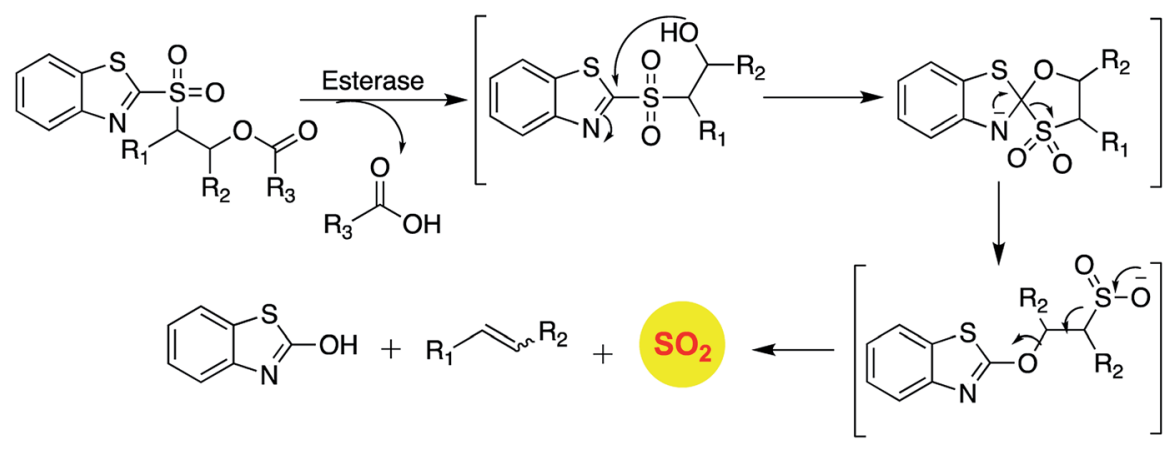

Scheme 12 Esterase activated $\mathrm{SO}_{2}$ donors based on Julia olefination. 
Reactive oxygen species (ROS) are another major redox regulator that have been found to be involved in many pathophysiological processes and regulating them has enormous implications in disease biology. ${ }^{\mathbf{1 5 9 - 1 6 2}}$ While these reactive species have been looked at in isolation, they are often connected and can regulate each other both positively and negatively. Thus, the study of reactive species is often complicated by poor detection techniques, artefacts and uncharacterized cellular interactions. Nevertheless, the quest for efficient and benign methods for generating reactive species with minimal footprint will strengthen our understanding of the associated complex biology.

\section{Conflicts of interest}

The authors declare no conflicts of interest.

\section{Acknowledgements}

The authors thank the Department of Science and Technology (DST, Grant number EMR/2015/000668), Department of Biotechnology, India (BT/PR15848/MED/29/1025/2016) for financial support for our research. Council for Scientific and Industrial Research (CSIR) and the Department of Science and Technology - Innovation in Science Pursuit for Inspired Research (DST-INSPIRE) for fellowships.

\section{Notes and references}

1 M. Bouroushian, in Electrochemistry of Metal Chalcogenides, Monographs in Electrochemistry, Springer Berlin Heidelberg, Berlin, Heidelberg, 2010, pp. 57-75.

2 T. V Mishanina, M. Libiad and R. Banerjee, Nat. Chem. Biol., 2015, 11, 457.

3 O. Kabil, V. Vitvitsky and R. Banerjee, Annu. Rev. Nutr., 2014, 34, 171-205.

4 C. Nathan and A. Cunningham-Bussel, Nat. Rev. Immunol., 2013, 13, 349-361.

5 S. Bruce King, Free Radical Biol. Med., 2013, 55, 1-7.

6 H. Kimura, Antioxid. Redox Signaling, 2015, 22, 347-349.

7 F. Gallyas, Br. J. Pharmacol., 2012, 166, 2228-2230.

8 A. Martelli, L. Testai, M. C. Breschi, C. Blandizzi, A. Virdis, S. Taddei and V. Calderone, Med. Res. Rev., 2012, 32, 10931130.

9 R. Pietri, A. Lewis, R. G. León, G. Casabona, L. Kiger, S.-R. Yeh, S. Fernandez-Alberti, M. C. Marden, C. L. Cadilla and J. López-Garriga, Biochemistry, 2009, 48, 4881-4894.

10 P. Nicholls and J.-K. Kim, Can. J. Biochem., 1982, 60, 613623.

11 A. K. Mustafa, M. M. Gadalla, N. Sen, S. Kim, W. Mu, S. K. Gazi, R. K. Barrow, G. Yang, R. Wang and S. H. Snyder, Sci. Signaling, 2009, 2, ra72.

12 M. H. Tatjana and K. G. Manfred, FEBS J., 2008, 275, 33523361.

13 M. Libiad, P. K. Yadav, V. Vitvitsky, M. Martinov and R. Banerjee, J. Biol. Chem., 2014, 289, 30901-30910.
14 T. P. Singer and E. B. Kearney, Arch. Biochem. Biophys., 1956, 61, 397-409.

15 B. T. Hofstaetter, P. Gronski, E. J. Kanzy, H. U. Schorlemmer, F. R. Seller and A. G. Behringwerke, Vox Sang., 2009, 45, 144-154.

16 W. W. C. Chan, Biochemistry, 1968, 7, 4247-4254.

17 M. H. Stipanuk, Annu. Rev. Nutr., 1986, 6, 179-209.

18 W. J. Mueller and S. Naeem, FEBS J., 2013, 280, 3050-3057.

19 N. B. Schwartz, S. Lyle, J. D. Ozeran, H. Li, A. Deyrup, K. Ng and J. Westley, Chem.-Biol. Interact., 1998, 109, 143-151.

20 H. M. Logan, N. Cathala, C. Grignon and J.-C. Davidian, J. Biol. Chem., 1996, 271, 12227-12233.

21 P. Pacher, J. S. Beckman and L. Liaudet, Physiol. Rev., 2007, 87, 315-424.

22 H. Cheng, L. Wang, M. Mollica, A. T. Re, S. Wu and L. Zuo, Cancer Lett., 2014, 353, 1-7.

23 A. Siegert, C. Rosenberg, W. D. Schmitt, C. Denkert and S. Hauptmann, Br. J. Cancer, 2002, 86, 1310-1315.

24 D. D. Thomas, L. A. Ridnour, J. S. Isenberg, W. FloresSantana, C. H. Switzer, S. Donzelli, P. Hussain, C. Vecoli, N. Paolocci, S. Ambs, C. A. Colton, C. C. Harris, D. D. Roberts and D. A. Wink, Free Radical Biol. Med., 2008, 45, 18-31.

25 L. J. Ignarro, G. Cirino, A. Casini and C. Napoli, J. Cardiovasc. Pharmacol., 1999, 34, 879.

26 D. A. Wink and J. B. Mitchell, Free Radical Biol. Med., 1998, 25, 434-456.

27 R. M. J. Palmer, A. G. Ferrige and S. Moncada, Nature, 1987, 327, 524-526.

28 D. A. Wink, H. B. Hines, R. Y. S. Cheng, C. H. Switzer, W. Flores-Santana, M. P. Vitek, L. A. Ridnour and C. A. Colton, J. Leukocyte Biol., 2011, 89, 873-891.

29 B. Bonavida, S. Khineche, S. Huerta-Yepez and H. Garban, Drug Resist. Updates, 2006, 9, 157.

30 K. Abe and H. Kimura, J. Neurosci., 1996, 16, 1066-1071.

31 L. K. Wareham, R. K. Poole and M. Tinajero-Trejo, J. Biol. Chem., 2015, 290, 18999-19007.

32 H. Niknahad and P. J. O'Brien, Chem.-Biol. Interact., 2008, 174, 147.

33 A. F. Gunnison, Food Cosmet. Toxicol., 1981, 19, 667.

34 C. S. Ough and E. A. Crowell, J. Food Sci., 1987, 52, 386. 35 B. L. Wedzicha, Chemistry of Sulphur Dioxide in Foods, 1984. 36 M. A. Amerine, H. W. Berg, R. E. Kunkee, C. S. Ough, V. L. Singleton and A. D. Webb, Technology of Wine Making, 1980.

37 J. Li and Z. Meng, Nitric Oxide, 2009, 20, 166.

38 K. Hanaoka, K. Sasakura, Y. Suwanai, S. Toma-Fukai, K. Shimamoto, Y. Takano, N. Shibuya, T. Terai, T. Komatsu, T. Ueno, Y. Ogasawara, Y. Tsuchiya, Y. Watanabe, H. Kimura, C. Wang, M. Uchiyama, H. Kojima, T. Okabe, Y. Urano, T. Shimizu and T. Nagano, Sci. Rep., 2017, 7, 40227.

39 C. D. McCune, S. J. Chan, M. L. Beio, W. Shen, W. J. Chung, L. M. Szczesniak, C. Chai, S. Q. Koh, P. T.-H. Wong and D. B. Berkowitz, ACS Cent. Sci., 2016, 2, 242-252.

40 J. L. Wallace and R. Wang, Nat. Rev. Drug Discovery, 2015, 14, 329-345. 
41 J. L. Wallace, Trends Pharmacol. Sci., 2007, 28, 501-505.

42 J. L. Wallace, L. Vong, W. McKnight, M. Dicay and G. R. Martin, Gastroenterology, 2009, 137, 569-578.e1.

43 R. Wang, Physiol. Rev., 2012, 92, 791-896.

44 Y. Zhao, T. D. Biggs and M. Xian, Chem. Commun., 2014, 50, 11788-11805.

45 A. A. Powolny and S. V Singh, Cancer Lett., 2018, 269, 305314.

46 K. Rahman, J. Nutr., 2001, 131, 977S-979S.

47 J. A. Milner, in Adv. Exp. Med. Biol., Springer US, Boston, MA, 2001, pp. 69-81.

48 G. A. Benavides, G. L. Squadrito, R. W. Mills, H. D. Patel, T. S. Isbell, R. P. Patel, V. M. Darley-Usmar, J. E. Doeller and D. W. Kraus, Proc. Natl. Acad. Sci. U.S.A, 2007, 104, 17977-17982.

49 Y.-Q. Cheng, G.-L. Tang and B. Shen, J. Bacteriol., 2002, 184, 7013-7024.

50 S. Sivaramakrishnan and K. S. Gates, Bioorganic Med. Chem. Lett., 2008, 18, 3076-3080.

51 C. Jacob, A. Anwar and T. Burkholz, Planta Med., 2008, 74, 1580-1592.

52 E. G. Mueller, Nat. Chem. Biol., 2006, 2, 185.

53 Z. J. Song, M. Y. Ng, Z.-W. Lee, W. Dai, T. Hagen, P. K. Moore, D. Huang, L.-W. Deng and C.-H. Tan, Medchemcomm, 2014, 5, 557-570.

54 W. Giggenbach, Inorg. Chem., 1971, 10, 1333-1338.

55 T. Ozturk, E. Ertas and O. Mert, Chem. Rev., 2007, 107, 52105278.

56 H. Z. Lecher, R. A. Greenwood, K. C. Whitehouse and T. H. Chao, J. Am. Chem. Soc., 1956, 78, 5018-5022.

57 F. Spiller, M. I. L. Orrico, D. C. Nascimento, P. G. Czaikoski, F. O. Souto, J. C. Alves-Filho, A. Freitas, D. Carlos, M. F. Montenegro, A. F. Neto, S. H. Ferreira, M. A. Rossi, J. S. Hothersall, J. Assreuy and F. Q. Cunha, Am. J. Respir. Crit. Care Med., 2010, 182, 360-368.

58 C. Fee, D. C. Gard and D. R. Yang, in Kirk-Othmer Encyclopedia of Chemical Technology, John Wiley \& Sons, New York, 2005.

59 Z. W. Lee, J. Zhou, C.-S. Chen, Y. Zhao, C.-H. Tan, L. Li, P. K. Moore and L.-W. Deng, PLoS One, 2011, 6, e21077.

60 L. Li, M. Whiteman, Y. Y. Guan, K. L. Neo, Y. Cheng, S. W. Lee, Y. Zhao, R. Baskar, C.-H. Tan and P. K. Moore, Circulation, 2008, 117, 2351-2360.

61 A. Sparatore, G. Santus, D. Giustarini, R. Rossi and P. Del Soldato, Expert Rev. Clin. Pharmacol., 2011, 4, 109-121.

62 M. V. Chan and J. L. Wallace, Am. J. Physiol.: Gastrointest. Liver Physiol., 2013, 305, G467-G473.

63 C. J. Gargallo and A. Lanas, J. Dig. Dis., 2012, 14, 55-61.

64 G. Caliendo, G. Cirino, V. Santagada and J. L. Wallace, J. Med. Chem., 2010, 53, 6275-6286.

65 L. Li, P. Rose and P. K. Moore, Annu. Rev. Pharmacol. Toxicol., 2011, 51, 169-187.

66 L. Li, G. Rossoni, A. Sparatore, L. C. Lee, P. Del Soldato and P. K. Moore, Free Radical Biol. Med., 2007, 42, 706-719.

67 Y. Zhao, H. Wang and M. Xian, J. Am. Chem. Soc., 2011, 133, 15-17.
68 Y. Zhao, S. Bhushan, C. Yang, H. Otsuka, J. D. Stein, A. Pacheco, B. Peng, N. O. Devarie-Baez, H. C. Aguilar, D. J. Lefer and M. Xian, ACS Chem. Biol., 2013, 8, 1283-1290.

69 T. Roger, F. Raynaud, F. Bouillaud, C. Ransy, S. Simonet, C. Crespo, M.-P. Bourguignon, N. Villeneuve, J.-P. Vilaine, I. Artaud and E. Galardon, ChemBioChem, 2013, 14, 22682271.

70 A. Martelli, L. Testai, V. Citi, A. Marino, I. Pugliesi, E. Barresi, G. Nesi, S. Rapposelli, S. Taliani, F. Da Settimo, M. C. Breschi and V. Calderone, ACS Med. Chem. Lett., 2013, 4, 904-908.

71 Y. Zhao, J. Kang, C.-M. Park, P. E. Bagdon, B. Peng and M. Xian, Org. Lett., 2014, 16, 4536-4539.

72 J. Kang, Z. Li, C. L. Organ, C.-M. Park, C. Yang, A. Pacheco, D. Wang, D. J. Lefer and M. Xian, J. Am. Chem. Soc., 2016, 138, 6336-6339.

73 N. O. Devarie-Baez, P. E. Bagdon, B. Peng, Y. Zhao, C.-M. Park and M. Xian, Org. Lett., 2013, 15, 2786-2789.

74 N. Fukushima, N. Ieda, K. Sasakura, T. Nagano, K. Hanaoka, T. Suzuki, N. Miyata and H. Nakagawa, Chem. Commun., 2014, 50, 587-589.

75 S. Y. Yi, Y. K. Moon, S. Kim, S. Kim, G. Park, J. J. Kim and Y. You, Chem. Commun., 2017, 53, 11830-11833.

76 Y. Venkatesh, J. Das, A. Chaudhuri, A. Karmakar, T. K. Maiti and N. D. P. Singh, Chem. Commun., 2018, 54, 3106-3109.

77 Z. Xiao, T. Bonnard, A. Shakouri-Motlagh, R. A. L. Wylie, J. Collins, J. White, D. E. Heath, C. E. Hagemeyer and L. A. Connal, Chem.-Eur. J., 2017, 23, 11294-11300.

78 Y. Zheng, B. Yu, K. Ji, Z. Pan, V. Chittavong and B. Wang, Angew. Chem., Int. Ed., 2016, 55, 4514-4518.

79 P. Shukla, V. S. Khodade, M. SharathChandra, P. Chauhan, S. Mishra, S. Siddaramappa, B. E. Pradeep, A. Singh and H. Chakrapani, Chem. Sci., 2017, 8, 4967-4972.

80 K. Shatalin, E. Shatalina, A. Mironov and E. Nudler, Science, 2011, 334, 986-990.

81 S. Elliott, E. Lu and F. S. Rowland, Environ. Sci. Technol., 1989, 23, 458-461.

82 H. W. Thompson, C. F. Kearton and S. A. Lamb, J. Chem. Soc., 1935, 1033-1037.

83 T. Ogawa, K. Noguchi, M. Saito, Y. Nagahata, H. Kato, A. Ohtaki, H. Nakayama, N. Dohmae, Y. Matsushita, M. Odaka, M. Yohda, H. Nyunoya and Y. Katayama, J. Am. Chem. Soc., 2013, 135, 3818-3825.

84 A. K. Steiger, S. Pardue, C. G. Kevil and M. D. Pluth, J. Am. Chem. Soc., 2016, 138, 7256-7259.

85 Y. Zhao and M. D. Pluth, Angew. Chem., Int. Ed., 2016, 55, 14638-14642.

86 Y. Zhao, H. A. Henthorn and M. D. Pluth, J. Am. Chem. Soc., 2017, 139, 16365-16376.

87 A. K. Steiger, Y. Yang, M. Royzen and M. D. Pluth, Chem. Commun., 2017, 53, 1378-1380.

88 C. R. Powell, J. C. Foster, B. Okyere, M. H. Theus and J. B. Matson, J. Am. Chem. Soc., 2016, 138, 13477-13480.

89 P. Chauhan, P. Bora, G. Ravikumar, S. Jos and H. Chakrapani, Org. Lett., 2017, 19, 62-65.

90 A. K. Steiger, M. Marcatti, C. Szabo, B. Szczesny and M. D. Pluth, ACS Chem. Biol., 2017, 12, 2117-2123. 
91 Y. Zhao, S. G. Bolton and M. D. Pluth, Org. Lett., 2017, 19, 2278-2281.

92 Y. Nakashima, S. Ohta and A. M. Wolf, Free Radical Biol. Med., 2017, 108, 300-310.

93 J. C. Foster, C. R. Powell, S. C. Radzinski and J. B. Matson, Org. Lett., 2014, 16, 1558-1561.

94 J. C. Foster and J. B. Matson, Macromolecules, 2014, 47, 5089-5095.

95 J. M. Carter, Y. Qian, J. C. Foster and J. B. Matson, Chem. Commun., 2015, 51, 13131-13134.

96 M. R. Filipovic, J. Zivanovic, B. Alvarez and R. Banerjee, Chem. Rev., 2018, 118, 1253-1337.

97 C.-M. Park, L. Weerasinghe, J. J. Day, J. M. Fukuto and M. Xian, Mol. BioSyst., 2015, 11, 1775-1785.

98 M. S. Vandiver, B. D. Paul, R. Xu, S. Karuppagounder, F. Rao, A. M. Snowman, H. Seok Ko, Y. Il Lee, V. L. Dawson, T. M. Dawson, N. Sen and S. H. Snyder, Nat. Commun., 2013, 4, 1626.

99 B. D. Paul and S. H. Snyder, Nat. Rev. Mol. Cell Biol., 2012, 13, 499.

100 T. Ida, T. Sawa, H. Ihara, Y. Tsuchiya, Y. Watanabe, Y. Kumagai, M. Suematsu, H. Motohashi, S. Fujii, T. Matsunaga, M. Yamamoto, K. Ono, N. O. Devarie-Baez, M. Xian, J. M. Fukuto and T. Akaike, Proc. Natl. Acad. Sci. U.S.A, 2014, 111, 7606-7611.

101 K. Ono, T. Akaike, T. Sawa, Y. Kumagai, D. A. Wink, D. J. Tantillo, A. J. Hobbs, P. Nagy, M. Xian, J. Lin and J. M. Fukuto, Free Radical Biol. Med., 2014, 77, 82-94.

102 J. I. Toohey, Anal. Biochem., 2011, 413, 1-7.

103 H. Kimura, Antioxid. Redox Signaling, 2014, 22, 347-349.

104 Y. Kimura, Y. Mikami, K. Osumi, M. Tsugane, J. Oka and H. Kimura, FASEB J., 2013, 27, 2451-2457.

105 T. Yamanishi and S. Tuboi, J. Biochem., 1981, 89, 19131921.

106 P. K. Yadav, M. Martinov, V. Vitvitsky, J. Seravalli, R. Wedmann, M. R. Filipovic and R. Banerjee, J. Am. Chem. Soc., 2016, 138, 289-299.

107 D. Zhang, I. Macinkovic, N. O. Devarie-Baez, J. Pan, P. Chung-Min, K. S. Carroll, M. R. Filipovic and M. Xian, Angew. Chem., Int. Ed., 2013, 53, 575-581.

108 N. Krishnan, C. Fu, D. J. Pappin and N. K. Tonks, Sci. Signaling, 2011, 4, ra86.

109 N. Sen, B. D. Paul, M. M. Gadalla, A. K. Mustafa, T. Sen, R. Xu, S. Kim and S. H. Snyder, Mol. Cell, 2012, 45, 13-24.

110 S. Longen, F. Richter, Y. Köhler, I. Wittig, K.-F. Beck and J. Pfeilschifter, Sci. Rep., 2016, 6, 29808.

111 É. Dóka, I. Pader, A. Bíró, K. Johansson, Q. Cheng, K. Ballagó, J. R. Prigge, D. Pastor-Flores, T. P. Dick, E. E. Schmidt, E. S. J. Arnér and P. Nagy, Sci. Adv., 2016, 2, e1500968.

112 T. Sawahata and R. A. Neal, Anal. Biochem., 1982, 126, 360364 .

113 B. Horst and Z. Gerwalt, Justus Liebigs Ann. Chem., 2006, 585, 142-149.

114 T. S. Bailey, L. N. Zakharov and M. D. Pluth, J. Am. Chem. Soc., 2014, 136, 10573-10576.
115 T. S. Bailey and M. D. Pluth, Free Radical Biol. Med., 2015, 89, 662-667.

116 N. E. Heimer, L. Field and J. A. Waites, J. Org. Chem., 1985, 50, 4164-4166.

117 E. Cuevasanta, M. Lange, J. Bonanata, E. L. Coitiño, G. Ferrer-Sueta, M. R. Filipovic and B. Alvarez, J. Biol. Chem., 2015, 290, 26866-26880.

118 D. K. Liu and S. G. Chang, Can. J. Chem., 1987, 65, 770-774. 119 A. Vasas, É. Dóka, I. Fábián and P. Nagy, Nitric Oxide, 2015, 46, 93-101.

120 G. S. Rao and G. Gorin, J. Org. Chem., 1959, 24, 749-753.

121 A. Isabelle and G. Erwan, ChemBioChem, 2014, 15, 23612364.

122 C.-M. Park, B. A. Johnson, J. Duan, J.-J. Park, J. J. Day, D. Gang, W.-J. Qian and M. Xian, Org. Lett., 2016, 18, 904-907.

123 J. Kang, A. J. Ferrell, W. Chen, D. Wang and M. Xian, Org. Lett., 2018, 20, 852-855.

124 Y. Zheng, B. Yu, Z. Li, Z. Yuan, C. L. Organ, R. K. Trivedi, S. Wang, D. J. Lefer and B. Wang, Angew. Chem., Int. Ed., 2017, 56, 11749-11753.

125 B. Yu, Y. Zheng, Z. Yuan, S. Li, H. Zhu, L. K. De La Cruz, J. Zhang, K. Ji, S. Wang and B. Wang, J. Am. Chem. Soc., 2018, 140, 30-33.

126 E. J. Emmett and M. C. Willis, Asian J. Org. Chem., 2015, 4, 602-611.

127 I. Marco, A. L. Thompson, H. Woolven, C. Gonz and M. C. Willis, Org. Lett., 2011, 2005-2007.

128 D. Wu and Z. Meng, Arch. Environ. Contam. Toxicol., 2003, 45, 423.

129 G. Qin and Z. Meng, Toxicol. Lett., 2005, 160, 34.

130 M. J. Pena-Egido, B. Garcia-Alonso and C. Garcia-Moreno, J. Agric. Food Chem., 2005, 53, 4198.

131 G. Paino-Campa, M. J. Peña-Egido and C. García-Moreno, J. Sci. Food Agric., 1991, 56, 85.

132 B. Garcia-Alonso, M. J. Pena-Egido and C. Garcia-Moreno, J. Agric. Food Chem., 2001, 49, 423.

133 P. Bisseret and N. Blanchard, Org. Biomol. Chem., 2013, 11, 5393-5398.

$134 \mathrm{H}$. Woolven, C. González-Rodríguez, I. Marco, A. L. Thompson and M. C. Willis, Org. Lett., 2011, 13, 4876-4878.

135 S. R. Malwal, D. Sriram, P. Yogeeswari, V. B. Konkimalla and H. Chakrapani, J. Med. Chem., 2012, 55, 553-557.

136 T. Fukuyama, M. Cheung, C.-K. Jow, Y. Hidai and T. Kan, Tetrahedron Lett., 1997, 38, 5831.

137 S. R. Malwal, D. Sriram, P. Yogeeswari and H. Chakrapani, Bioorg. Med. Chem. Lett., 2012, 22, 3603-3606.

138 E. Ge, M. Fan, H. Qiu, H. Hu, L. Tian, X. Wang, G. Xu and X. Wei, Environ. Pollut., 2017, 228, 408-415.

139 K. A. Pardeshi, S. R. Malwal, A. Banerjee, S. Lahiri, R. Rangarajan and H. Chakrapani, Bioorg. Med. Chem. Lett., 2015, 25, 2694-2697.

140 M.-Y. Wu, K. Li, C.-Y. Li, J.-T. Hou and X.-Q. Yu, Chem. Commun., 2014, 50, 183-185.

141 P. Vogel, M. Turks, L. Bouchez, D. Marković, A. VarelaÁlvarez and J. Á. Sordo, Acc. Chem. Res., 2007, 40, 931-942. 
142 F. Jung, M. Molin, R. Van der Elzen and T. Durst, J. Am. Chem. Soc., 1974, 96, 935-936.

143 W. Wang, X. Ji, Z. Du and B. Wang, Chem. Commun., 2017, 53, 1370-1373.

144 X. Ji, E. M. El-labbad, K. Ji, D. S. Lasheen, R. A. T. Serya, K. A. Abouzid and B. Wang, Org. Lett., 2017, 19, 818-821.

145 W. Wang and B. Wang, Chem. Commun., 2017, 53, 1012410127.

146 S. R. Malwal and H. Chakrapani, Org. Biomol. Chem., 2015, 13, 2399-2406.

147 R. Kodama, K. Sumaru, K. Morishita, T. Kanamori, K. Hyodo, T. Kamitanaka, M. Morimoto, S. Yokojima, S. Nakamura and K. Uchida, Chem. Commun., 2015, 51, 1736-1738.

148 S. R. Malwal, M. Gudem, A. Hazra and H. Chakrapani, Org. Lett., 2013, 15, 1116-1119.

149 J. J. Day, Z. Yang, W. Chen, A. Pacheco and M. Xian, ACS Chem. Biol., 2016, 11, 1647-1651.

150 K. A. Pardeshi, G. Ravikumar and H. Chakrapani, Org. Lett., 2018, 20, 4-7.

151 L. K. Keefer, ACS Chem. Biol., 2011, 6, 1147-1155.

152 G. Ferrer-Sueta and R. Radi, ACS Chem. Biol., 2009, 4, 161177.
153 C. Szabo, H. Ischiropoulos and R. Radi, Nat. Rev. Drug Discovery, 2007, 6, 662-680.

154 K. Sharma, A. Iyer, K. Sengupta and H. Chakrapani, Org. Lett., 2013, 15, 2636-2639.

155 A. E. Maciag, J. E. Saavedra and H. Chakrapani, Anti-Cancer Agents Med. Chem., 2009, 9, 798.

156 J. E. Saavedra, T. R. Billiar, D. L. Williams, Y.-M. Kim, S. C. Watkins and L. K. Keefer, J. Med. Chem., 1997, 40, 1947-1954.

157 A. T. Dharmaraja, G. Ravikumar and H. Chakrapani, Org. Lett., 2014, 16, 2610-2613.

158 K. Sharma, K. Sengupta and H. Chakrapani, Bioorg. Med. Chem. Lett., 2013, 23, 5964-5967.

159 A. T. Dharmaraja, M. Alvala, D. Sriram, P. Yogeeswari and H. Chakrapani, Chem. Commun., 2012, 48, 10325-10327.

160 A. T. Dharmaraja and H. Chakrapani, Org. Lett., 2014, 16, 398-401.

161 A. T. Dharmaraja, C. Jain and H. Chakrapani, J. Org. Chem., 2014, 79, 9413-9417.

162 R. H. Ritchie, G. R. Drummond, C. G. Sobey, T. M. De Silva and B. K. Kemp-Harper, Pharmacol. Res., 2017, 116, 57-69. 